TR $-1797-3$

\title{
USER'S MANUAL FOR BIOSPHERE AND DOSE SIMULATION PROGRAM
}

\author{
(BIODOSE) \\ 4 January 1980
}

Prepared for:

THE UNIVERSITY OF CALIFORNIA Lawrence Livermore Laboratocy Livermore, California

Under Subcontract No. 4250209

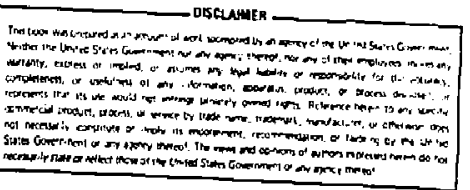

Prepared by:

John J. Duffy Gary P. Bogar

Approved by:

John Bartlett

Gary W. Good

THE ANALYTIC SCIENCES CORPORATION

Six Jacob Way

Reading, Massachusetts 01867 


\section{PREFACE}

This user's manual documents the BICaccumulation and DOSE prediction (BIODOSE) comput $=r$ program developed for Lawrence Livermore Labc atory. The authors wish to acknowledge the contribut: ins to the development of the BIODOSE model and program of Charles Koplik, Stephen Hodgin, Gary Good, and Kathryn Baribeau of TASC. 


\section{TABLE OF CONTENTS}

$\begin{array}{lc}\text { PREFACE } & \begin{array}{c}\text { Page } \\ \text { No. }\end{array} \\ \text { List of Figures } & i \mathrm{i} \\ \text { List of Tables } & \mathrm{v} \\ \mathrm{v}\end{array}$

1. INTRODUCTION 1-1

1.1 Purpose $1=1$

1.2 Model Description 1-1

1.2.1 Radionuclide Concentrations in Compartments 1-4

1.2.2 Potential Hazard Calculations $1-13$

1.2.3 Mode1 Assumptions $1-26$

2. PROGRAM DESCRIPTION 2-1

2.1 Introduction 2-1

2.2 Main Program BIODOSE 2-1

2.3 Subroutine INPUT - Data Input Controller 2-3

2.3.1 Subroutine INVRD - Nuclide Inventory $2-4$

$\begin{array}{ll}2.3 .2 & \text { Subroutine INIT - Non-Standard Dose } \\ \text { Factor Initialization } & 2-4\end{array}$

2.3.3 Subroutine NUCOUT - Nuclide Data
Input Summary

2.4 Subroutine COMPUT - Computation Controller 2-5

2.4.1 Subroutine USERAT - Compartment Usage
Rate Computation $2-6$

2.4.2 Subroutine CALC - Potential Hazard
Rate Computation

2.4.3 Subroutine CONCNT - Quasi-Steady-State 2-6

$2: 4.4$ Subroutine EQUAL - Steady-State
Computation

2.4.5 Subroutine SETUP - Compartment Flow
Rates Computation

2.4 .6 Subroutine TIMVAR - Time-Varying
Computation

2.4.7 Subroutine EIGRF - Eigenvalues and
Eigenvector Computation

2.4.8 Subroutine DOSE - Potential Hazards
Summation

2.4.9 Subroutine PRNT - Potential Hazards
Report Printer 


\section{TABLE OF CONTENTS (Continued)}

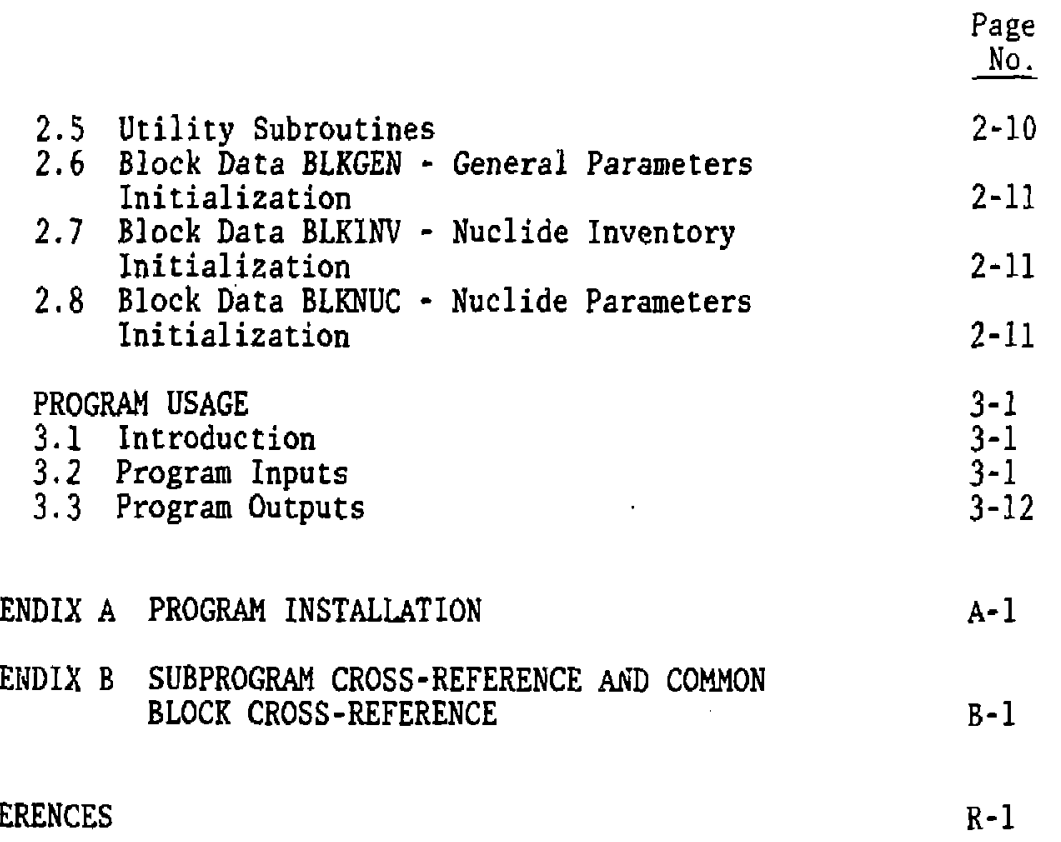

REEERENCES 


\section{LIST OF FIGURES}

Figure

No.

1.2-1 BIODOSE Water and Food Pathways Model: River,

Estuary and Ocean System

No.

2.2-1 BIODOSE Block Diagram

\section{LIST OF TABLES}

Table

No.

1.2-1 Dose Categories and Subcategories

1.2-2 Organ Code List

1.2-3 Compartment Codes

2.3-1 Namelist and Labeled Common Blocks

3.2-1 BIODOSE Iuput Data Summary, Systen Parameters (Namelist/SYSLST/)

3.2-2 BIODOSE Input Data Summary, Animal Parameters (Namelist/ANLST/)

3.2-3 BIODOSE Input Data Summary, Soil Parameters (Namelist/SOILST/)

3.2-4 BIODOSE Input Data Summary, Usage Pa'ameter (Namelist/ULST/)

3.2-5 BIODOSE Inpuc Data Summary, Vegetable Parameters (Namelist/VEGLST/)

3.2-6 BIODOSE Input Data Summary, Water Parameters (Namelist/WLST/)

3.2-7 Nuclide Parameters (Namelist/NUCLST/)

3.2-8 Inventory Input (Namelist/INVLST/) 
1. INTRODUCTION

1.1 PURPOSE

This user's manual describes the BIOsphere Transport and DOSE program (BIODOSE) prepared for, and delivered to, Lawrence Livermore Laboratory (LLL) by The Analytic Sciences Corporation (TASC). BIODOSE simulates the transport of radionuclides in surface water systems and the resulting concentration of nuclides in the food chain. It includes the prediction of human dosage risks for individuals and for populations resulting from release of radionuclides into surface water or well water. The BIODOSE program was designed for easy use, including standard defaults and a flexible input scheme.

\subsection{MODEL DESCRIPTION}

The BIODOSE model predicts doses to humans from releases of radionuclides io the surface environment. It simulates soil and water bodies as perfectly mixed compartments with many dose pathways to man including aquatic food, crops, animal products, drinking water and ground exposure. Figure 1.2-1 schematically depicts the moce?. Air pathways were not considered. The model is described in detail in Appendix $G$ of Ref. 1. Key model assumptions and equations solved in the model are given here in a form consistent with the computations as performed in the computer program.

The time frame of the model simulations is currently set at five million years. The basic conditions and parameters 


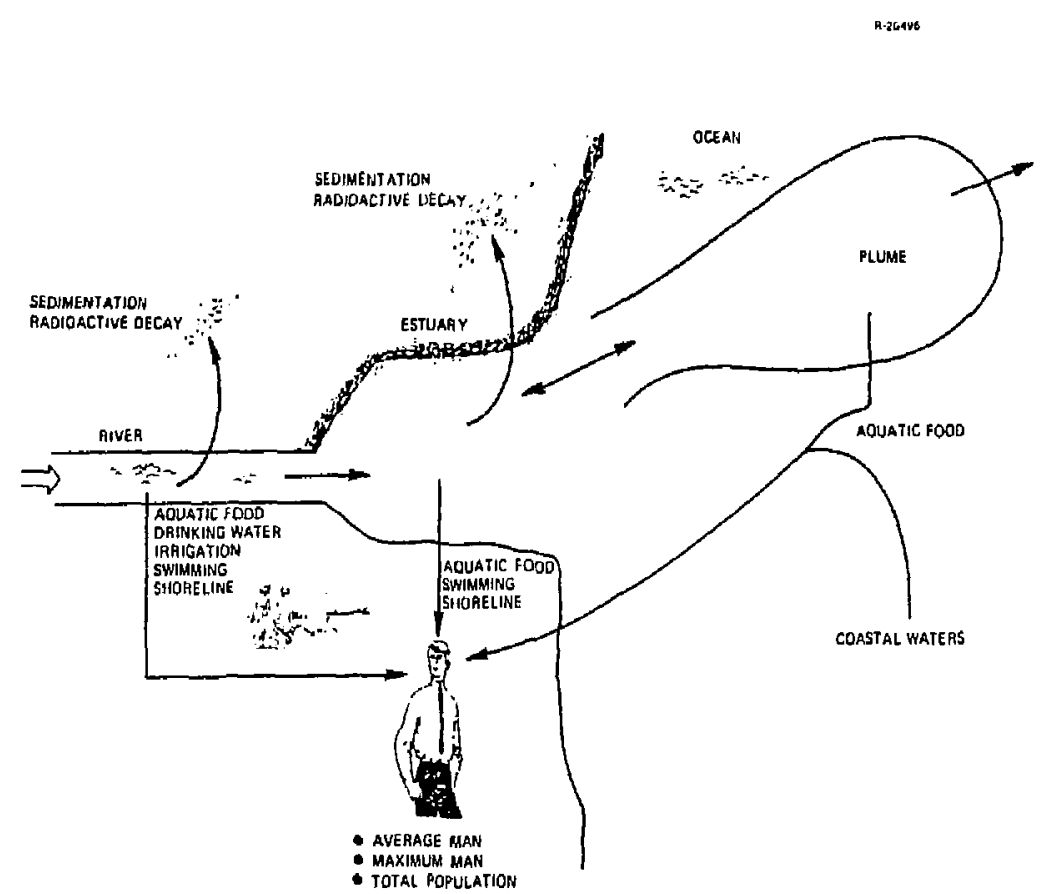

Figure 1.2-1 BIODOSE Water and Food Pathways Model: River, Estuary and Ocean System

(such as physical flow rates between compartments and food usage rates) are assumed to be unchanged during this time period. Lack of information about future conditions makes this assumption reasonable. However, different hypothesized scenarios can be modeled and tested with the program.

Conceptually, the model solves two basic types of equations: one describing the concentration of radionuclides in surface water compartments resulting from releases into them, and the other relating human organ doses to these compartment concentrations via various pathways. These equations are: 


$$
\begin{aligned}
& V \frac{d \underline{C}_{r}}{d t}=-\lambda_{r} V C_{r}+A_{r} C_{r}+Q_{r}+\sum_{s} \lambda_{r} V C_{s} \\
& D_{r \ell u}=C_{r \ell} U_{\ell} D F_{r \ell u}
\end{aligned}
$$

where

$\underline{C}_{r} \quad$ is a vector of dimension $n$ whose components are the concentrations of nuclide $r$ in the $n$ compartments $\left(\mathrm{Ci} / \mathrm{m}^{3}\right)$

$\lambda_{r}$ is the radioactive decay constant for nuclide $r\left(\mathrm{yr}^{-1}\right)$. Note that $\lambda_{\mathrm{s}}$ does not enter into the equation for nuclide $r$ because concentrations are given in curies

$A_{r}$ is the matrix of volumetric flow rates with the off-diagonal elements $a_{i j}$ representing transfer from compartment $j$ to compartment $i$ and the diagonal elements $a_{i i}$ being the flow rates out of compartment $i\left(\mathrm{~m}^{3} / \mathrm{yr}\right)$

$Q_{\mathbf{r}}$ is the vector of inputs to the compartments (Ci/yr)

$\mathrm{V}$ is a diagonal matrix whose elements are the compartment volumes $\left(\mathrm{m}^{3}\right)$

$s$ is a subscript labeling those nuclides which decay into nuclide $r$

$D_{\text {reu }}$ is the dose rate to organ $u$ from nuclide $r$ from compartment $\mathfrak{f}$ (rem)

$\mathrm{C}_{\mathrm{rl}}$ is the concentration of nuclide $r$ in compartment \& $\left(\mathrm{Ci} / \mathrm{m}^{3}\right)$

$\mathrm{U}_{\ell}$ is the usage rate associated with compartment $\ell\left(\mathrm{m}^{3}\right)$

$\mathrm{DF}_{\mathrm{rlu}}$ is the radiation dose factor for nuclide $r$ in compartment $\ell$ for organ $u$ (rem per $C i$ ) 
A normalized input of radionuclides is used in the model: the waste resulting :rom one megawat-electric-year of power production per year. Thus, the model predictions are expressed as potential hazards. To obtain dose predictions, account. must be taken of the predicted inputs to the water system. The manner in which the inputs can be taken into account is discussed in Section 1.2.1, along with the compartment concentration calculations. The potential hazard calculations are discussed in Section 1.2.2.

\subsubsection{Radionuclide Concentrations in Compartments}

Equation 1.2-1 can be simplified by expressing the concentrations as ratios to the cotal inventory of that nuclide, viz.,

$$
\underline{c}_{r}=\underline{c}_{r} / I_{r}
$$

where $I_{r}$ is the total amount ( $C i$ ) of nuclide $r$ from the waste in existence anywhere at a given time. The differential equation for $I_{r}$ can be written as

$$
\frac{d I}{d t}=-\lambda_{r} I_{r}+\Delta \lambda_{s} \lambda_{r} I_{s}
$$

Combining the above equations yields

$$
V \frac{d c_{r}}{d t}=A_{r} c_{r}+\frac{Q_{r}}{\bar{I}_{r}}+\sum \lambda_{s} \frac{I_{s} V}{I_{r}}\left(\underline{c}_{s}-\underline{c}_{r}\right)
$$

It is assumed that $\underline{c}_{r}(0)=\underline{c}_{s}(0)=0$; that is, nuclide $r$ and its parents are not present in the compartments at time zero. By the uniqueness theorem for differential equations, $\underline{c}_{r}=c_{s}$ if the compartment flow matrix is the same for both nuclide $r$ 
and nuclide $s$. Therefore if $A_{r}=A_{s}$ for any $s$ (which is assumed in all the cases which follow),

$$
\frac{d c}{d t}=v^{-1} A_{r-r}+v^{-1} q_{r}
$$

where $g_{r}=\frac{g_{r}}{I_{r}}$. The compartment equations are thus simplified by expressing the radionuclide concentrations as proportions of total inventory and thereby avoiding analysis of decay chains.

The user should be aware that the compartment flow matrices $\left(A_{r}\right)$ are not identical for every nuclide in a decay chain in the default values of $A_{r}$ in BIODOSE. The distribution coefficients for the sediment compartments, the retardation factors for the topsoil, and the crop removal rates are included in the compartment flow matrix $A_{r}$ (see Eq. 1.2-8 below) and vary for each nuclide in the default versicn of BIODOSE. The effect of this deviation from the underlying assumption of the compartment concentration model is believed to be relatively minor with the default BIODOSE parameters. However, the user should beware of changing distribution coefficients or retardation factors of nuclides in the same decay chain to widely varying values without further analysis of the effects on potential hazard predictions.

The BIODOSE model has parameter values set to simulate a large river in the Northwestern United States. However, the parameter values can be relatively easily changed for other water body systems (Ref. 1). Seven compartments are included: river water, river sediment, copsoil, estuary water, estuary sediment, plume water, and ocean water. The radionuclide concentration vector for the Northwestern river is: 
THE ANALYTIC SCIENCES CORPORATION

$$
\underline{c}_{r}=\left[c_{r w} c_{r t} c_{r s} c_{r e} c_{r s e} c_{r p} c_{r o}\right]^{T}
$$

and $T$ denotes transpose and the subscripts $w, t, s$, e, se, $p$, and o represent river water, topsoil, river sediment, estuary water, estuary sediment, plume water and ocean water, respecLively. The differential equations used in the model to describe the radionuclide concentrations in each of the compactmints are the following:

$$
\begin{aligned}
& v_{w} \frac{d c_{r w}}{d t}=-\left[F+I+\frac{D A}{d}+k_{r s} A_{s} v_{w}\right] c_{r w}+q_{r} \\
& +\left(\frac{\mathrm{I}+\mathrm{R}-\mathrm{E}}{\mathrm{B}_{\mathrm{rt}}}\right) \mathrm{c}_{r t}+\left(\frac{\mathrm{DA} \mathrm{s}_{\mathrm{s}}}{\mathrm{R}_{r s} \mathrm{~d}}\right) c_{r s} \\
& v_{s} \frac{d c_{r s}}{d t}=-\left[\frac{D A_{s}}{d K_{r s}}+A_{s} v_{w}+I R_{s}\right] c_{r s}+\left(S_{t} A_{t}\right) c_{r t} \\
& +\left[\frac{D A_{s}}{d}+K_{r s} A_{s} v_{w}\right] c_{r w} \\
& v_{t} \frac{d c_{r t}}{d t}=-\left[\frac{I+R-E}{B_{r t}}+M_{r}+S_{t} A_{t}\right] c_{r t}+I c_{r w} \\
& +I R_{s} c r s \\
& v_{e} \frac{d c_{r e}}{d t}=-\left[\frac{v_{e}}{T_{e}}+\frac{D A}{d}+k_{r s e} A_{e} v_{e}\right] c_{r e}+F c_{r w} \\
& +\left(\frac{D A_{e}}{K_{r s e} d}\right) c_{r s e}
\end{aligned}
$$

$1-6$ 


$$
\begin{aligned}
& v_{s e} \frac{d c_{r s e}}{d t}=-\left[\frac{D A_{e}}{K_{r s e}}+A_{e} v_{e}\right] c_{r s e}+\left[\frac{D A_{e}}{d}+K_{r s e} A_{e} v_{t}\right] c_{r e} \\
& v_{p} \frac{d c_{r p}}{d t}=-(10 F) c_{r p}+\frac{v_{e}}{T_{e}} c_{r e} \\
& v_{0} \frac{d c_{r o}}{d t}=-\left[\left(1-\frac{A_{p}}{A_{0}}\right)_{\frac{0}{T_{0}}}^{V_{0}}\right] c_{r o}+\left[10 F-\frac{V_{p}}{T_{0}}\right] c_{r p}
\end{aligned}
$$

If these equations are put in the matrix form of Eq. 1.2-6, the transfer coefficient matrix, $V^{-1} A_{r}$, becomes:

$$
V^{-1} A_{r}=\left[\begin{array}{ccccccc}
a_{11} & a_{12} & a_{13} & 0 & 0 & 0 & 0 \\
I / N_{t} & a_{22} & a_{23} & 0 & 0 & 0 & 0 \\
a_{31} & a_{32} & a_{33} & 0 & 0 & 0 & 0 \\
F / N_{e} & 0 & 0 & a_{44} & a_{45} & 0 & 0 \\
0 & 0 & 0 & a_{54} & a_{55} & 0 & 0 \\
0 & 0 & 0 & a_{64} & 0 & a_{66} & 0 \\
0 & 0 & 0 & 0 & 0 & a_{76} & a_{77}
\end{array}\right]
$$

where

$$
\begin{aligned}
& a_{11}=-\left[F+I+\frac{D A_{s}}{d}+K_{r s} A_{s} v_{w}\right] / v_{w} \\
& a_{12}=(I+R-E) /\left(\theta B_{r t} v_{w}\right) \\
& a_{13}=\frac{D A_{s}}{d K_{r s} v_{w}}
\end{aligned}
$$




$$
\begin{aligned}
& a_{22}=-\left((I+R-E) / B_{r t}{ }^{\theta}+M_{r}+A_{t} S_{t} J / N_{t}\right. \\
& a_{23}=I R_{s} N_{t} \\
& a_{31}=\left[\frac{D A_{s}}{d}+k_{r s} A_{s} v_{w}\right] N_{s} \\
& a_{32}=A_{t} S_{t} / N_{S} \\
& a_{33}=-\left[\frac{D A_{s}}{d K_{r s}}+A_{s} v_{w}+I R_{s}\right] / N_{s} \\
& a_{44}=-\left[\frac{V_{e}}{T_{e}}+\frac{D A_{e}}{d}+k_{r s e} A_{e} V_{\epsilon}\right] N_{\epsilon} \\
& a_{45}=\frac{D A_{e}}{d K_{r s e} V_{e}}
\end{aligned}
$$

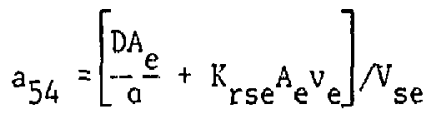

$$
\begin{aligned}
& a_{55}=-\left[\frac{\mathrm{DA}_{e}}{\mathrm{~K}_{\text {rse }} \mathrm{d}^{\mathrm{d}}}+\mathrm{A}_{\mathrm{e}} \mathrm{v}_{e}\right] \mathrm{N}_{\mathrm{se}} \\
& a_{64}=V_{e} /\left(T_{e} V_{p}\right) \\
& a_{66}=-(10 \mathrm{~F}) / \mathrm{N}_{\mathrm{p}} \\
& a_{76}=\left[10 F-v_{p} / T_{0}\right] / N_{0} \\
& a_{77}=-\left[\left(1-A_{D} / A_{0}\right) / T_{0}\right]
\end{aligned}
$$


and

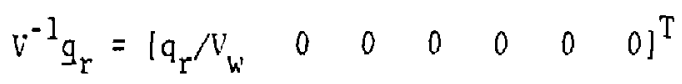

where $V_{\ell}$ is the effective volume of compartment $\ell$
[Vol(l)]

$A_{\ell}$ is the surface area of compartment $\ell$

$K_{\text {rl }}$ is the distribution coefficient of compartment $l$, which is the ratio of the volumetric concentration in the dry sediment to that in the water [FKS,FKE]

$T_{\ell}$ is the flushing time of compartment $\ell$ [TE, TO]

$\mathrm{q}_{\mathrm{r}}$ is the input of nuclide $r$ from the aquifer connecting the repository to the water body $[\operatorname{VIN}(r)]$

$v_{\ell}$ is the net rate of sedimentation from compartment $\ell$ [SRATE, SERATE]

$F$ is the net outflow rate of the river (or lake) [FLOW]

$I$ is the average yearly rate at which water is withdrawn from the river (or lake) for irrigation [WRATE]

$D$ is the average diffusion coefficient [DC]

$\mathrm{d}$ is the average diffusion depth [DD]

$R$ is the average yearly rainfall on the topsoil [KA]

$E$ is the average yearly evapotranspiration from the topsoil [ET]

$M_{I}$ is the effective average yearly removal rate of nuclide :- from the topsoil that is taken up by piants [REMOVL( $r)]$

$S_{t}$ is the erosion rate of topsoil [ERATE] 


\section{$\theta$ is the volumetric water content of topsoil [THETA] \\ $\mathrm{B}_{\mathrm{rt}}$ is the retardation factor for topsoil, i.e., $(1+K / \theta)$, where the parameters are defined abov'e [1/FRT]}

The names in brackets are the labels used in the program code if different from the algebraic symbol used here.

Three different methods of solution of the set of compartnent equations $(1.2-6)$ are available in the simulation model: quasi-steady-state with the topsoil radionuclide buildup over a relatively short time period, steady-state, and timevarying for all the compartmenis with continuous topsoil nuclide buildup. The three solution options are described below.

Quasi-Steady-State-Solution - The quasi-steady-state solution takes into account the effect of nuclide buildup in the topsoil. In this solution, the tcosoil concentration is treated as time-varying, while the concentrations in the remainder of the compartments are considered to be in the equilibrium state. The topsoil buildup time can be long compared with changes in the inpur. In this simulation model it is assumed that irrigation takes place every year to a maximum limit (currently set at one thousand years). For times lacer than that maximum limit, it is assumed that irrigation took place only over the preceding time period equal to the maximum limit (one thousand years). The limited irrigation period is intended to simulate the limited period during which the hypothetical nuclear waste is expected to be released into the river (Ref. 1). This limitation of irrigation allows expected doses to be estimated by simply multiplying the BIODOSE potential hazard outputs by the predicted nuclear waste input to the river (in units of MWe-yr/yr). 
The quasi-steady state solution to the compartment equations is the following:

$$
c_{r t}=\frac{b}{a}\left(\exp \left(a t_{b}\right)-1\right)
$$

where

$$
\begin{aligned}
& a=\int-\left(\frac{I+R-E}{B_{r t}}+M_{r}+A_{t} S_{t}\right)+\frac{1}{K_{2}} S_{t} A_{t} I R_{S} \\
& \left.+\left[\frac{\frac{I+R-E}{B_{r t} \theta}+\frac{D A_{s} S_{t} A_{t}}{K_{r s} d K_{2}}}{K_{I}-\frac{D A_{s}}{K_{r s} d K_{2}}\left(K_{r s} A_{s} v_{w}+\frac{D A_{s}}{d}\right)}\right]\left[1+\frac{I R_{s}}{K_{2}} \frac{D A_{s}}{d}+k_{r s} A_{s} v_{w}\right)\right] v_{t} \\
& b=\left\{\frac{I+\frac{I R_{s}}{K_{2}}\left(\frac{D A_{s}}{d}+K_{r s} A_{s} v_{w}\right)}{K_{l}-\frac{D A_{s}}{K_{r s} d K_{2}}\left(K_{r s} A_{s} v_{w^{\prime}}+\frac{D A s}{d}\right)}\right\} \frac{q_{r}}{V_{t}} \\
& K_{1}=F+I+\frac{D A}{d}+K_{r s} A_{s} v_{w} \\
& K_{2}=\frac{D A_{s}}{K_{r s} d}+A_{s} v_{w}+I R_{s} \\
& c_{r w}=\frac{q_{r}+\left(\frac{I+R-E}{B_{r t} \theta}+\frac{D A_{s} S_{t} A_{t}}{K_{r s} d k_{2}}\right) c_{r t}}{k_{1}-\frac{D A_{s}}{k_{r s} d K_{2}}\left(K_{r s} A_{s} v_{w}+\frac{D A}{d}\right)}
\end{aligned}
$$




$$
\begin{aligned}
& c_{r s}=\frac{1}{k_{2}}\left|A_{t} S_{i} c_{r t}+\left(\frac{D A_{s}}{d}+K_{r s} A_{s} v_{w}\right) c_{r w}\right| \\
& c_{r e}=\left(F T_{e} / N_{e}\right) c_{r w} \\
& c_{r p}=\left[\left(v_{e} /\left(T_{e} 10 F\right)\right] c_{r e}\right.
\end{aligned}
$$

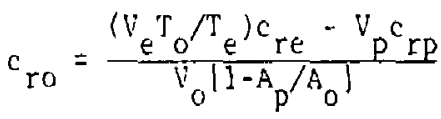

$$
\begin{aligned}
& c_{\text {rse }}=k_{\text {rse }} c_{\text {re }} \\
& t_{b}= \begin{cases}t / T & \text { if } t<T_{m} \\
T_{m} & \text { if } t>T_{m}\end{cases}
\end{aligned}
$$

where $T$ (TRVLS) is an interval factor between irrigations, and $\mathrm{T}_{\mathrm{m}}$ (TMAX) is the maximum limit of irrigation time.

The quasi-steady-state solution for a well system is the following:

$$
\begin{aligned}
& c_{r w}=a_{r} \\
& c_{r t}=\left(1 c_{r w} / N_{t}\right)\left[1-\exp \left(-L_{r} t_{b}\right)\right] / L_{r}
\end{aligned}
$$

where

$$
L_{r}=\frac{I+R-E}{K_{r t} V_{t}}+\frac{M_{r}}{V_{t}}+\frac{A_{t} S_{t}}{V_{t}}
$$

Steady-State Solutions - The dynamics of the assumed water body systems are reasonably fast relative to input changes 
except for the topsoil and sediment compartments. That is, for all the water body compartments, the time to reach a steadystace concentration is short compared with the time period over which past studies (Ref. 1) indicate that changes take place in the waste input to the compartment system. The sediment compartments contribute a minor amount to overall hazard. Consequently, a steady-state, or equilibrium, solution to those cumpartment equations is appropriate for simulations of those systems in which the topsoil compartment is not significant. The steady-state solution to Eq. 1.2-6 is:

$$
c_{r}=-A_{r}^{-1} g_{r}
$$

To obtain predicted doses, the potential hazard predictions resulting from this solution method can be simply multiplied by the expected waste input into the river.

Time-Varying Solution - With this solution, the radionuclide concentrations in all the compartments are assumed to vary in time in response to input changes. This solution method provides a more realistic simulation compared to the other methods. It may result in a less conservative prediction of potential hazard. 1t, like the steady-state method, is flexible in the sense of ease in changing the compartment transfer rate terms (in $V^{-1} A$ of Eq. 1.2-8). The quasi-steady-state solution requires that a closed-form solution to the compartment concentration equations (Eq. 1.2-6) be rederived after changes are made in the transfer rate terms (other than just changing the numerical values of existing parameters). The method is less flexible than the steady-state method in the sense that the radioactive input function (release rate from the repository into the biosphere) should be put into the compartment solution equations (see below) before the hazard is computed. With the steady-state or the quasi-steady-state 
solution the predicted input and the potential hazard can be computed separately and then simply multiplied together. The simulation presently has an annual jnput of the waste resulting from one MWe-yr of power production.

The time-varying solution to the compartment equation (Eq. 1.2-8) with zero initial conditions is the following:

$$
c_{r}(t)=\exp \left(V^{-1} A_{r} t\right) \int_{0}^{t} \exp \left(-V^{-1} A_{r} \tau\right) V^{-1} g_{r} d \tau
$$

Since the nuclide input $q_{r}$ is treated as a piecewise constant function and the nuclide amounts are evaluated at discrete time points for computational purposes, Eq. 1.2-17 may be discretized:

$$
\begin{aligned}
\underline{s}_{r}\left(t_{N}\right)= & \sum_{i=1}^{N} \mid \exp \left[V^{-1} A_{r}\left(t_{N}-\ddots_{i-1}\right)\right] \\
& -\exp \left[V^{-1} A_{r}\left(t_{N}-t_{i}\right)\right] \mid\left(V^{-1} A_{r}\right)^{-1} V^{-1} g_{r}\left(t_{i}\right)
\end{aligned}
$$

where $t_{i}$ is the $i^{\text {th }}$ time point, $\left\langle g_{r}\left(t_{i}\right)\right.$ is constant between $t_{i-1}$ and $t_{i}$, and $N$ is the index of the time at which $c_{r}$ is to be evaluated.

Due to computational difficulties in the exponentiation of $V^{-1} A_{r} \Delta t$ for large values of $\Delta t$, an appropriate coordinate transformation of $\underline{c}_{r}$ is utilized to diagonalize the trans* formed $V^{-1} A_{r}$ matrix. Specifically, let

$$
\underline{c}_{r}=P_{r} y_{r}
$$


where $\mathrm{P}_{\mathrm{r}}$ is the matrix whose columns are eigenvectors of the matrix $\left(\mathrm{V}^{-1} \mathrm{~A}_{\mathrm{r}}\right)$. Substitution of Eq. 1.2-19 into Eq. 1.2-6 yields:

$$
\frac{d y_{r}}{d t}=D_{r} y_{r}+p_{r}^{-1} v^{-1} q_{r}
$$

where $D_{r}=P_{r}^{-1} V^{-1}{ }_{A_{r}} P_{r}$, which is a diagonal matrix of eigenvalues ccrresponding to the eigenvectors of $P_{r}$ if all the eigenvalues are distinct. This condition would srmally hold for all cases to be studied. Nevertheless, a warning message is printed if nondistinct eigenvalues are detected in the computer program. Equation 1.2-20 represents a set of $n$ decoupled scalar differential equations instead of a system of $n$ coupled differential equations as in Eq. 1.2-6.

The solution to Eq. 1.2-20 (analogous to Eq. 1.2-18) becomes:

$$
y_{r}^{j}\left(t_{N}\right)=\sum_{i=1}^{N} \exp \left[\lambda_{j}\left(t_{N}-t_{i-1}\right)\right]-\exp \left[\lambda_{j}\left(t_{N}-t_{i}\right)\right] \frac{1}{\lambda_{j}}\left[P_{r}^{-1} v^{-1} q_{r}\left(t_{i}\right)\right]_{j}
$$

where $y_{r}^{j}$ is the $j^{\text {th }}$ element of the vector $y_{r}$ and $\lambda_{j}$ is the corresponding eigenvalue and the notation $\left[\underline{x}_{j}\right.$ denotes the $j$ th element of vector $\underline{x}$. The original vector of nuclide concentrations, $c_{r}\left(t_{N}\right)$, can then be calculated via Eq. 1.2-19.

For a seven compartment system, to prevent numerical difficulties associated with having too large a range of eigenvalues of the $\left(\mathrm{V}^{-1} \mathrm{~A}_{\mathrm{r}}\right)$ matrix, the system is decoupled and two sets of equations are solved sequentially. The $\left(\mathrm{V}^{-1} \mathrm{~A}_{\mathrm{r}}\right)$ matrix in Eq. 1.2 .8 has a structure which readily lends itself to decoupling. The equations for the first three compartments can be solved independently of the last four compartmenc equations. 
Then, the system of equations for the last four cumpartments can be solved with the input to the estuary compartment being $\left(\mathrm{Fc} \mathrm{rw}_{\mathrm{w}}\right)$. The diathematical structure of each of the two subsystems is thus identical.

For any of the solution methods, once the concentration $s_{r}$ relative to the total inventory $I_{r}$ are obtained, concentrations in $\mathrm{Ci} / \mathrm{m}^{3}$ result from the following computation:

$$
\underline{c}_{r}={ }_{c_{r}}{ }_{r}
$$

\subsubsection{Potential Hazard Calculations}

The concentrations calculated for the five media: sediment, river, estuary, ocean and topsoil, are used with a simple ecosystem model to give radionuclide dose rates to man. Potential hazards are assumed to be received by ingestion and external exposure. The ingestion pathways considered are drinking water, aquatic foods, irrigated crops and farm animals. The external exposure pathways considered are shoreline, boating, swimming and topsoil.

For individual potential hazard predictions, each adult is assumed to drink all his water and eat all his aquatic food from the river or lake system into which radioactive material was released. Furthermore, each adult's diet is assumed to be composed solely of food products that were either directly or indirectly contaminated by the river or lake water. In addition, all water-related recreation time is assumed to be spent somewhere within the river, estuary and ocean system. These assumptions ensure that no important pathway for exposure is overlooked for each nuclide in the systen. 
The basic dose equation can be expressed as:

$$
D_{\text {rlua }}=G_{\text {rlua }} C_{\text {rl }}
$$

where

$$
\begin{aligned}
& D_{\text {reua }} \text { is the potential hazard to organ } u \text { from } \\
& \text { nuclide } r \text { from compartment } \ell \text { and exposure } \\
& \text { category a : } \\
& \mathrm{C}_{\mathrm{rl}} \text { is the concentration of nuclide } \mathrm{r} \text { in } \\
& G_{\text {rlua }} \text { is the dose rate per compartment } \ell \text { con- } \\
& \text { category a. }
\end{aligned}
$$

Doses are calculated for the whole body and seven organs of interest: gastrointestinal and lower large intes. tine, thyroid, bone, liver, lung, kidney and skin. The means of exposure includes immersion and surface irradiation as well as ingestion. A whole-body dose equivalent can also be calculated which combines the dose to all organs by using dose equivalent factors (Ref 2 ). These factors weight each organ dose according to cancer risk. This equivalent dose may provide a more meaningful and compact way of presenting the hazard from radioactive waste.

The dose rates per concentration, $G_{\text {rlua }}$, in Eq. 1.2-22 are decomposed in the model into exposure categories and subcategories, which are listed in Table 1.2-1. The dose rates per concentration (G) are functions of usage rates and dose factors. Let $U_{\text {rlab }}$ be the usage rate in compartment $\ell$ of category $a$ and subcategory $b$, and define $D_{r a u}$ as the dose factor for nuclide $r$ from category a to organ $u$. 
TABLE 1.2-1

DOSE CATEGORIES AND SUBCATEGORIES

\begin{tabular}{|c|c|c|c|}
\hline \multicolumn{2}{|c|}{ CATEGORY } & \multicolumn{2}{|c|}{ SUBCATEGORY } \\
\hline $\operatorname{CODE}(a)$ & NANE & $\operatorname{CODE}(b)$ & NAME \\
\hline 1 & $\begin{array}{l}\text { Exposure to plane } \\
\text { surfaces }\end{array}$ & & \\
\hline 2 & Immersion in water & & \\
\hline 3 & $\begin{array}{l}\text { Ingestion of aquatic } \\
\text { food }\end{array}$ & $\begin{array}{l}1 \\
2 \\
3\end{array}$ & \begin{tabular}{|l} 
Fish \\
Mollusk \\
Crustacean
\end{tabular} \\
\hline 4 & Ingestion of crops & $\begin{array}{r}1 \\
2 \\
3 \\
4 \\
5 \\
6 \\
7 \\
8 \\
9 \\
10\end{array}$ & $\begin{array}{l}\text { Leafy vegetables } \\
\text { Other above ground } \\
\text { vegatables } \\
\text { Potatoes } \\
\text { Other root vegetables } \\
\text { Berries } \\
\text { Melons } \\
\text { Orchard fruit } \\
\text { Wheat } \\
\text { Other grains } \\
\text { Grass }\end{array}$ \\
\hline 5 & $\begin{array}{l}\text { Ingestion of } \\
\text { drinking water }\end{array}$ & & \\
\hline 6 & $\begin{array}{l}\text { Ingestion of } \\
\text { animal products }\end{array}$ & $\begin{array}{l}1 \\
2 \\
3 \\
4 \\
5\end{array}$ & $\begin{array}{l}\text { Eggs } \\
\text { Milk } \\
\text { Beef } \\
\text { Pork } \\
\text { Poultry }\end{array}$ \\
\hline & & & \\
\hline
\end{tabular}

The dose factor is computed as follows:

$D_{\text {rau }}=18.7 \frac{f_{w} \varepsilon}{m} \frac{\lambda_{u r} t_{1}+\exp \left(-\lambda_{u r} t_{2}\right)-\exp \left(-\lambda_{u r}\left[t_{2}-t_{1}\right]\right)}{\lambda_{u r}^{2}}$ 
where

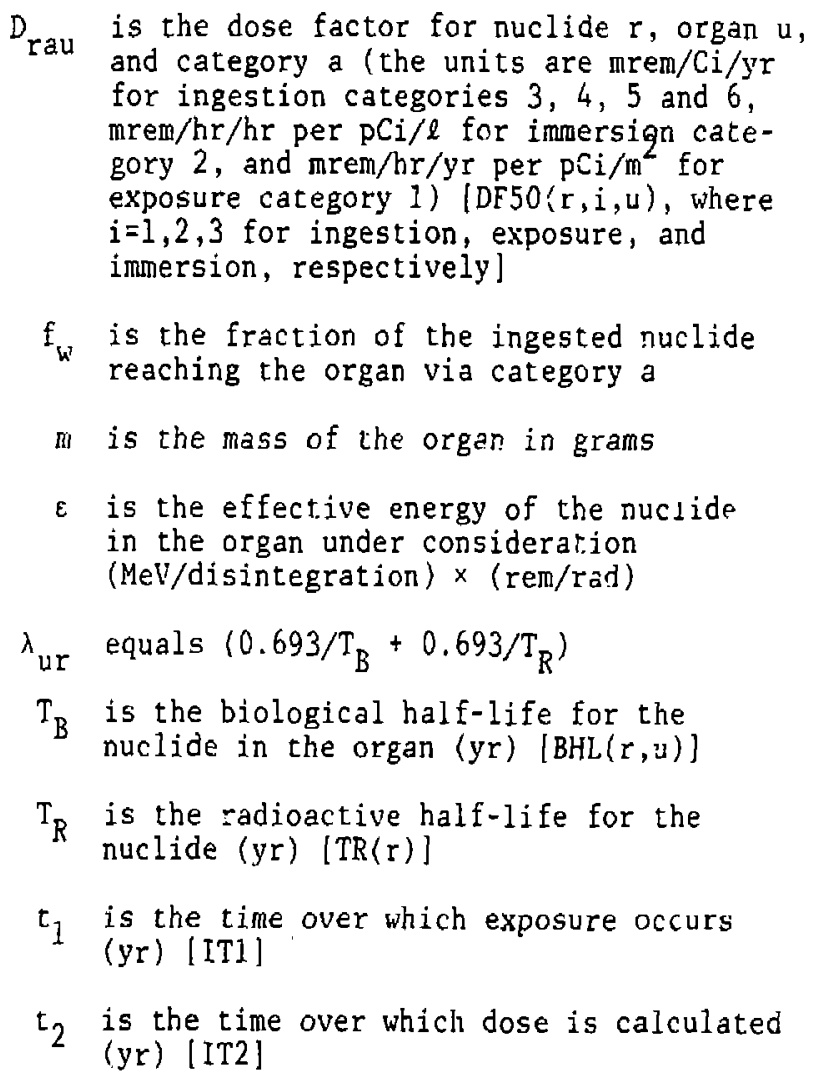

and $18 ?$ is the ractor which converts $\frac{\mathrm{MeV}}{\mathrm{dis}} \frac{\mathrm{rem}}{\mathrm{rad}} \frac{1}{\mathrm{gm}}$ to $\frac{\mathrm{mrem}}{\mathrm{yr}} \frac{1}{\mathrm{pCi}}$

The above parameters values were taken from Ref. 3 and personal communication from soldat". In the model the default values of $t_{1}$ and $t_{2}$ are fifty years. The dose factors are inputs to the program and are modified if $t_{1}$ and $t_{2}$ are not equal to

*J. Soldat, Battelle Pacific Northwest Laboratory. 
fifty years. If the time over which the dose is calculated remains at fifty years, the individual potential hazards are expressed in units of fifty-year doses in rem per unit input.

Individual Potential Hazards - The individual usage rates $\left(\mathrm{U}_{\ell \mathrm{ab}}\right)$ are inputs to the program and are in units of liters/yr, $\mathrm{kg} / \mathrm{yr}$, or hr/yre, depending on the category and subcategory. There are two sets of usage rates: for an individual with an average diet and one with a maximum diet.

The dose rates per concentration are compuled according to the equations below. Tables $1.2-2$ and $1.2-3$ list the organ codes and compartment codes for reference.

$$
G_{\text {rlul }}=10^{9} D_{r l u} U_{\ell 11}(S D) W_{\ell}, 5 \leq \ell \leq 7
$$

TABLE 1. 2-2

ORGAN CODE LIST

\begin{tabular}{|c|c|}
\hline $\operatorname{CODE}(u)$ & ORGAN NAME \\
\hline 1. & Whole body equivalent \\
\hline 2. & Whole body \\
\hline 3. & $\begin{array}{l}\text { Gastrointestinal and } \\
\text { lower large intestine } \\
\text { (GI-LLI) }\end{array}$ \\
\hline 4. & Thyroid \\
\hline 5. & Bone \\
\hline 6. & Liver \\
\hline 7. & Lung \\
\hline 8. & Kidney \\
\hline 9. & Skin \\
\hline
\end{tabular}


TABLE 1.2-3

COMPARTMENT CODES

\begin{tabular}{|c|l|}
\hline CODE $(\ell)$ & COMPARTMENT NAME \\
\hline 1. & River (or lake) water \\
2. & Estuary water \\
3. & Plume water \\
4. & Ocean water \\
5. & Topsoil \\
6. & River (or lake) sediment \\
7. & Estuary sediment \\
\hline
\end{tabular}

where

$$
\begin{aligned}
& 10^{9} \text { converts } \frac{\text { nIrem }}{\mathrm{pCi}} \text { to } \frac{\text { rem }}{\mathrm{Ci}} \\
& \mathrm{U}_{\ell 11} \text { is exposure usage in units of } \mathrm{hr} / \mathrm{yr} \\
& {\left[\mathrm{U}_{511}=8760, \mathrm{U}_{611}=\right.\text { SHORE] }} \\
& \mathrm{SD} \text { is the effective soil or shoreline depth (m) } \\
& \mathrm{W}_{2} \text { is the shielding factor for the topsoil } \\
& \text { (Ref. } 4) \text { and a shoreline - width factor } \\
& \text { for the sediment compartments (from Ref. 5). }
\end{aligned}
$$$$
G_{r \ell u 2}=10^{6} D_{r 2 u} U_{\ell 21}, 1 \leq \ell \leq 4
$$

where

$$
\begin{aligned}
& \mathrm{U}_{\ell 21} \text { is swimming usage in hr/yr }\left.\right|_{\ell 21}=\text { SWIM } \\
& \text { *SWIMT( }(2) \text {, where } \operatorname{SWIMT}(l) \text { is the fraction } \\
& \text { of swiming time per compartment] } \\
& 10^{6} \text { converts } \frac{\mathrm{mrem}}{\mathrm{pC} i / 2} \text { to } \frac{\mathrm{rem}}{\mathrm{Ci} / \mathrm{m}^{3}}
\end{aligned}
$$




$$
G_{r 2 u 3}=10^{6} D_{r 3 u} \sum_{b=1}^{3} U_{23 b} B_{r \ell b}, 1 \leq \ell \leq 4
$$

where

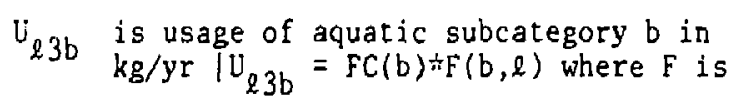

$$
\begin{aligned}
& \text { the fraction of food consumed from } \\
& \text { each compartment] } \\
& B_{r \ell b} \text { is a bioaccumulation factor ( } P C i / k g \\
& \text { biota per PCi/l of water) for fresh } \\
& \text { water for } \ell=1 \quad B(r, 2, b)] \text { and for } \\
& \text { salt water for } \ell=2,3,4[B(r, 1, b)] \\
& \text { and } \quad 10^{6} \text { converts } \frac{\text { mrem }}{\mathrm{PCi} / 2} \text { to } \frac{\text { rem }}{\mathrm{Ci}^{3} / \mathrm{m}^{3}}
\end{aligned}
$$

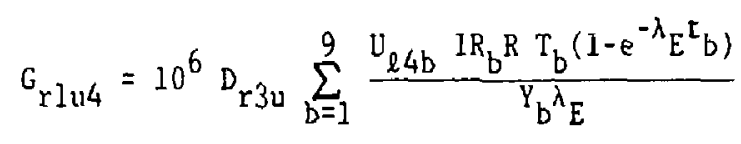
$t_{b}$ is the time of above-ground exposure of crops to contamination during the growing season (days) [TEXP $(b)]$


and $\mathrm{U}_{14 b}$ is the usage of crop $\mathrm{b}$ in $\mathrm{kg} / \mathrm{gr}[\mathrm{VC}(\mathrm{b})]$.

$$
G_{r 5 u 4}=10^{9} D_{r 3 u} \sum_{b=1}^{9} \frac{U_{54 b} B_{r}}{D_{T}}
$$

where

$$
\begin{aligned}
& { }^{B} \mathrm{r} \text { is the plant concentration factor, in } \mathrm{Ci} / \mathrm{kg} \\
& \text { wet weight of plant per } \mathrm{Ci} / \mathrm{kg} \text { dry weight of } \\
& \text { soil }[\mathrm{BV}(\mathrm{r})]
\end{aligned}
$$

$\mathrm{D}_{\mathrm{T}}$ is the bulk density of soil, in $\mathrm{kg} / \mathrm{m}^{3}, \mathrm{dry}$

and

$$
10^{9} \text { converts } \frac{\text { mrem }}{\mathrm{pC} \dot{i}} \text { to } \frac{\text { rem }}{\mathrm{C} \dot{i}}
$$

[Note that $\mathrm{U}_{14 \mathrm{~b}}=\mathrm{U}_{54 \mathrm{~b}} \cdot 1$

$$
G_{r 1 \mathrm{u} 5}=10^{6} \mathrm{D}_{\mathrm{r} 3 \mathrm{u}} \mathrm{U}_{151} \text { TREAT }_{r}
$$

where

and

$$
\begin{gathered}
\text { TREAT }_{r} \text { is the fraction of nuclide } r \text { remaining } \\
\text { in drinking water after treatment } \\
\mathrm{U}_{151} \text { is the usage rate of drinking water for } \\
\text { humans [WC] }
\end{gathered}
$$

$$
\begin{aligned}
10^{6} \text { converts } \frac{\mathrm{mrem}}{\mathrm{pCi} / \mathrm{l}} \text { to } \frac{\mathrm{rem}}{\mathrm{pCi} / \mathrm{m}^{3}} \\
\mathrm{G}_{\mathrm{rlu} 6}=10^{6} \mathrm{D}_{\mathrm{r} 3 \mathrm{u}}\left(\sum_{\mathrm{b}=1}^{5} \mathrm{U}_{16 \mathrm{~b}} \mathrm{~S}_{\mathrm{rb}} \mathrm{QF}_{\mathrm{b}}\right) \frac{\mathrm{IR}_{10^{\mathrm{RT}} 10}\left(1-e^{\left.-\lambda_{\mathrm{E}} \mathrm{t} 10\right)}\right.}{\mathrm{Y}_{10} \lambda_{\mathrm{E}}} \\
\left.+\sum_{\mathrm{b}=1}^{5} \mathrm{U}_{16 \mathrm{~b}} \mathrm{~S}_{\mathrm{rb}} \mathrm{Qw}_{\mathrm{b}}\right)
\end{aligned}
$$

where

$\mathrm{IR}_{10}, \mathrm{~T}_{10}, \mathrm{t}_{10}, \mathrm{Y}_{10}$, and $\mathrm{R}$ are parameters defined in Eq. 6.2-27 for the grass crop which it is 
conservatively assumed makes up the total diet for animals

$S_{r b}$ is the transfer coefficient of nuclide $r$ from daily intake of animal to edible portion of animal product, in days/ $\ell$ for milk and days/kg for other animal products $[S A(r, b)]$

$\mathrm{QF}_{\mathrm{b}}$ is the consumption rate of contaminated feed (grass) by an animal in $\mathrm{kg} /$ day $[Q F(b)]$

$Q W_{b}$ is the consumption rate of water by an animal ia $\ell /$ day $[Q W(b)]$

$10^{6}$ is the conversion factor to obtain $\frac{\mathrm{rem}}{\mathrm{ci} / \mathrm{m}^{3}}$

and

$$
\begin{aligned}
& \mathrm{U}_{16 \mathrm{~b}} \text { is the usage rate of animal product } \mathrm{b} \\
& {[A C(\mathrm{~b})]}
\end{aligned}
$$

$$
G_{r 5 u 6}=10^{9} D_{r 3 u}\left(\sum_{b=1}^{5} U_{56 b} S_{r b} Q F_{b}\right)^{\frac{B_{r}}{D_{T}}}
$$

where the parameters have been defined above and $U_{16 b}=U_{56 b}$. INote that two usage rates exist in the program: one for the individual with an average diet and one for the individual with a maximum diet. The two different sets of values are clearly labeled in the "input summary" listing of the program output, shown in Table 3.2-4.]

Individual Potential Hazard from Wells - The calculations of dose factors per concentrations for a well water system are identical to the above except that only compartment 1 (well water) and compartment 5 (topsoil) are considered. It is assumed that the well water is used for irrigation of top* soil and for drinking water. Also, immersion and ingestion of aquatic food are not considered. It is assumed that the input is the nuclide concentration in the well water or that a unit well flow rate exists (one $\mathrm{m}^{3} / \mathrm{yr}$ ) or that the output is divided 
by the well flow rate." The potential hazard to individuals from nuclide $r$ to organ $u$ at time $t$ is computed as follows:

$$
P_{r u}(t)=\sum_{a} \sum_{\ell} D_{r \ell u a}(t)
$$

Population Potential Hazard - The population potential hazards per year are predicted in a manner similar to that for the individual hazards except that the usage factors (U) are computed on a population basis rather than an individual basis. The individual rates $\left(U_{\ell a b}\right)$ used in Eqs. 1.2-24 through 1.2-31 are replaced with the following expressions for population usage:

$$
\mathrm{D}_{\ell 11}=\mathrm{USER}_{\ell} \mathrm{A}_{\ell}, \ell=6,7
$$

where

$$
\begin{aligned}
& \text { USER }_{\ell} \text { is the number of hours spent in com- } \\
& \text { partment } \ell \text { per year per square meter } \\
& \text { of compartment } \ell[\text { USER }(\ell)] \text { and } A_{\ell} \text { is } \\
& \text { the area of compartment } \ell \\
& \qquad U_{511}=\text { USER }_{5} P A_{5}
\end{aligned}
$$

where

$P$ is the population density on the topsoil (number $/ \mathrm{m}^{2}$ ) [POPDEN]

$$
\begin{aligned}
& \mathrm{p}_{\ell 21}=\mathrm{USER}_{\ell} A_{\ell}, 1 \leq \ell \leq 4 \\
& \mathrm{p}_{\ell 3 \mathrm{~b}}=\mathrm{H}_{\mathrm{b} \ell}, 1 \leq \ell \leq 4
\end{aligned}
$$

\footnotetext{
"If BIODOSE is to be used with the WASTE program, the input should be $\mathrm{Ci} / \mathrm{yr}$ from one MWe-yr/yr, as the WASTE output units are $\mathrm{Ci} / \mathrm{MWe}-\mathrm{yr} / \mathrm{yr} / \mathrm{m}^{3}$ and BIODOSE units are rem per Ci/MWe $-\mathrm{yr} / \mathrm{m}^{3}$ for a fifty-year dose.
} 
where

$\mathrm{H}_{\mathrm{bl}}$ is the fish harvest in $\mathrm{kg} / \mathrm{yr}$ from compart-

$$
p_{\ell 4 b}=\frac{10^{3} U_{\ell 4 b} f_{v} I}{\left(\sum_{b=1}^{9} \frac{U_{\ell 4 b} I R_{b} t_{b}}{Y_{b}}\right)}
$$

where

$\mathrm{U}_{\ell 4 \mathrm{~b}}$ is the average individual usage rate of
crop $\mathrm{b}$ in $\mathrm{kg} / \mathrm{yr}[\mathrm{VC}(1, \mathrm{~b})]$

$f_{v}$ is the fraction of the irrigation

rate that is used for irrigating crops for human consumption [FVEG]

$F$ is the river (or well) flow rate in $\mathrm{m}^{3} / \mathrm{yr}$ [FLOW]

$I_{r}, t_{b}$, and $Y_{b_{3}}$ are defined in Eq. $1.2-27$

1000 converts $\mathrm{m}^{3}$ to liters

and the denominator term represents the number of kilograms of crop produced per liter of irrigation water

$$
\mathrm{p}_{151}=10^{3} \mathrm{f}_{\mathrm{d}} \mathrm{F}
$$

where

$$
\begin{aligned}
& f_{d} \begin{array}{l}
\text { is the fraction of river (or well) flow } \\
\text { rate used by humans for drinking water } \\
\text { [FDRINK] }
\end{array} \\
& { }_{p}^{U_{\ell 6 b}}=\frac{10^{3} \mathrm{f}_{b} I Y_{10} R_{b}}{I_{10} t_{10} Q_{b}}, \ell=1,5
\end{aligned}
$$

where 
$f_{b}$ is the fraction of irrigation rate that is used for irrigating crops for consumption by animals for producing product $b[F I R(b, c)$, where $c=1$ for river and $c=2$ for well]

$R_{b}$ is the production rate of product $b$ in $\mathrm{kg}$ (or $\&$ for milk) per animal per day [RATE(b)]

$\mathrm{Y}_{10}, \mathrm{IR}_{10}, \mathrm{t}_{10}$ are yield parameters for animal feed (grass)

and 1000 converts $\mathrm{m}^{3}$ to liters.

It is assumed for internal model consistency that the sum of the total of the fractions of irrigation water used for crops for humans and animals must equal one; i.e..

$$
\left[f_{v}+\sum_{b=1}^{9} f_{b}\right]=1.0
$$

Also. the equation for $G_{r l u 6}$ for the population hazard per compartment concentration is changed from $\mathrm{Eq} \cdot 1.2-30$ to the following:

$$
\begin{aligned}
& G_{r l u 6}=10^{6} D_{r 3 u}\left\{\left(\sum_{b=1}^{5} p_{16 b}^{U} S_{r b} Q F_{b}\right) \frac{1 R_{10}^{R T} 10^{\left(1-e^{-\lambda} E^{t} 10\right)}}{Y_{10} \lambda_{E}}\right. \\
& \left.+\left(\sum_{b=1}^{5} g_{b} F R_{b} S_{r b}\right)\right\}
\end{aligned}
$$

where

$q_{f}$ is the fraction of river (or well) water

flow used as drinking water for animal product $b[\operatorname{FDR}(b, c)$, where $c=1$ and $c=2$ for wel1]. 
Fron the above expressions it is evident that, except for topsoil exposure, the population potential hazard predictions are independent of population density assumptions. For calculations of population doses far into the future it is very difficult to make realistic population estimates. However, the total potential hazard from some pathways will be essentially independent of the size of the neighboring population. The aquatic food pathway depends on the net fish harvest and the vegetable and animal pathways primarily depend on the yearly irrigation rate. The population potential hazard from these pa hways will be independent of how these products are distributed. That is, the population potential hazard is the same if a small number of individuals in the population consume all the contaminated products or if many individuals each consume only a small part of the contaminated products.

The total crop uptake (used in the compartment concentration calculations) is computed according to the following equation:

$$
\begin{aligned}
& M_{r}=10^{3} \mathrm{I}\left[\sum_{b=1}^{5} \frac{S_{r b}{ }_{r} f_{b}{ }^{y_{10}} R_{b}}{D_{T}{ }^{I R_{10} t_{10}}}\right. \\
& \left.+\frac{\sum_{b=1}^{9} B_{r} U_{54 b} f_{v}}{D_{T} \sum_{b=1}^{9} \frac{U_{54 b}{ }^{I R_{b} t_{b}}}{\mathrm{Y}_{b}}}\right]
\end{aligned}
$$

where

$\mathrm{M}_{-}$is the total crop uptake of water removed from the topsoil in $\mathrm{m}^{3} / \mathrm{yr}$ and all the other parameters have been defined previously. 
Potential hazards to populations are expressed in terms of annual doses rather than fifty-year doses. The population is assumed to have approximately a uniform distribution of ages. As radionuclide releases are apprcximately constant for time periods on the order of fifty years, a population will at any time contain equal numbers of individuals who have been exposed for each number of years from one to fifty. The dose in one year to fifty individuals, each of whom has been exposed for a different number of years, is equal to the dose over fifty years to one individual. Since the $D_{\text {rlua }}$ represent accumulated fifty-year doses, a division of fifty (or $\tau_{2}$ if different from $f$ ifty) is necessary in the case of population potential hazards to obtain an annual dose. For releases to surface water systems, the potential hazard to the population is therefore given by

$$
P_{r e}(t)=\frac{1}{t_{2}} \sum_{a} \sum_{l} D_{r \& u a}(t)
$$

Population Potential Hazard from $w: 1 \mathrm{ls}$ - The potential hazard predictions from the well water system are the same as for the river or lake system except that only the well water compartment (1) and topsoil compartment (5) are considered. In addition, immersion and ingestion of aquatic food are not considered. Also, the parameters $f_{v}, f_{b}, g, I$ and $F$ are replaced with values appropriate for well systems.

In the case of population doses from wells, a somewhat different formula is used for the potential hazard:

$$
P_{r u}(t)=\frac{1}{t_{2} Q_{w}} \sum_{a} \sum_{L} D_{\text {reua }}(t)
$$

where $Q_{w}$ is the well water flow rate $\left(m^{3} / y r\right)$ (WRATE(2)). This division by $Q_{w}$ makes the potential hazard independent of well 
water withdrawal rate and makes the uutput compatible with the NUTRAN programs WASTE and WPPLOT so that they can be run with values of $Q_{w}$ different from the value used in BIODOSE (Ref. 7).

\section{Potential Hazards Pathway Categorization - The poten-}

tial hazards for either irdividuals or population can be grouped according to several different criteria: individual nuclide, body organ, water system compartment, exposure category, and the three nuclide categories based on retardation factors in aquifer media. The potential hazards may be grouped according to any of the above criteria or most combinations, as explained in Section 3.3.

\section{Short-Lived Daughters - Certain daughter nuclides} considered in BIODOSE have half-lives which are sufficiently short that essentially all of their potential hazard can be attributed to the parent decaying in che biosphere subsequent to input to surface waters. In BIODOSE the potential hazards of some short-lived daughters are added to those of their parents unless the parameter NODAUT is set equal to FALSE. These are listed in Table 1.2-4. The nuclide $\mathrm{cm}^{242}$ is included in the list because after about one hundred years it is essentially in secular equilibrium with $\mathrm{Am}^{242 \mathrm{~m}}$.

\subsubsection{Model Assumptions}

Several key assumptions of the aiodel, which should be noted in interpreting the simulation results, are summarized here for convenience:

- Water and soil bodies are modeled as perfectly-mixed compartments with firstorder transfer rates

- Radionuclide doses are linear functions of concentration 
TABLE $1.2-4$

SHORT-LIVED DAUGHTERS WHOSE POTENT IAL HAZARDS ARE ADDED TO THOSE OF PARENTS FOR PRINTOUT

\begin{tabular}{|c|c|c|}
\hline DAUGHTER & PARENT & $\begin{array}{c}\text { HALF - LIFE } \\
\text { (DAYS) }\end{array}$ \\
\hline \hline $\mathrm{Y}^{90}$ & $\mathrm{Sr}^{90}$ & 2.7 \\
$\mathrm{Sb}^{126}$ & $\mathrm{Sn}^{126}$ & 12.4 \\
$\mathrm{Cm}^{242}$ & $\mathrm{Am}^{242 \mathrm{~m}}$ & 160 \\
$\mathrm{~Np}^{239}$ & $\mathrm{Am}^{243}$ & 2.4 \\
$\mathrm{Ac}^{225}$ & $\mathrm{Ra}^{225}$ & 10.0 \\
\hline
\end{tabular}

- The annual rate at which radionuclides enter the water body is normalized to be the waste from one MWe-yr of power production

- The potential population hazard predictions are expressed as doses per year to the population from a fifty-year exposure per unit of waste entering the water system in units of man-rem

- The prtential individual hazard predic. tions are expressed as fifty-year doses to individuals eating an average or maximun diet of food, all of which is from contaminated areas, per unit of waste entering the water system per year, in units of rem

- To convert potential hazards to doses, the rate at which waste enters the water system must be taken into account. 
2.

\section{PROGRAM DESCRIPTION}

\subsection{INTRODUCTION}

The BIODOSE progran is written in ANSI FORTRAN with the NAMELIST option and four-dimensional arrays. It consists of 26 subprograms: 3 BLOCK DATA units, 19 computational routines, and 4 utility routines. It was designed top-down, with highest levels performing sequencing functions. Computations are performed at lower levels. Since the modules communicate large amounts of data, labeled COMMONs were used to avoid unwieldy subroutine calls. The actual code is highly structured to enhance understanding and ease of maintenance with comments, mnemonic lables and indentation.

Section 2.2 of this chapter describes the main program. Sections 2.3 through 2.9 describe data input (INPUT), computation control (COMPUT), report output (OUTPUT), general parameters initialization (BLKGEN), nuclide inventory initialization (BLKINV), and nuclide parameters initialization, respectively.

\subsection{MAIN PROGRAM BIODOSE}

The main program, BIODOSE, performs the highest level sequencing, it calls the input routine (INPUT), the main computational routine (COMPUT), and output routine (OUTPUT). The overall program structure is shown in Fig. 2.2-1. 


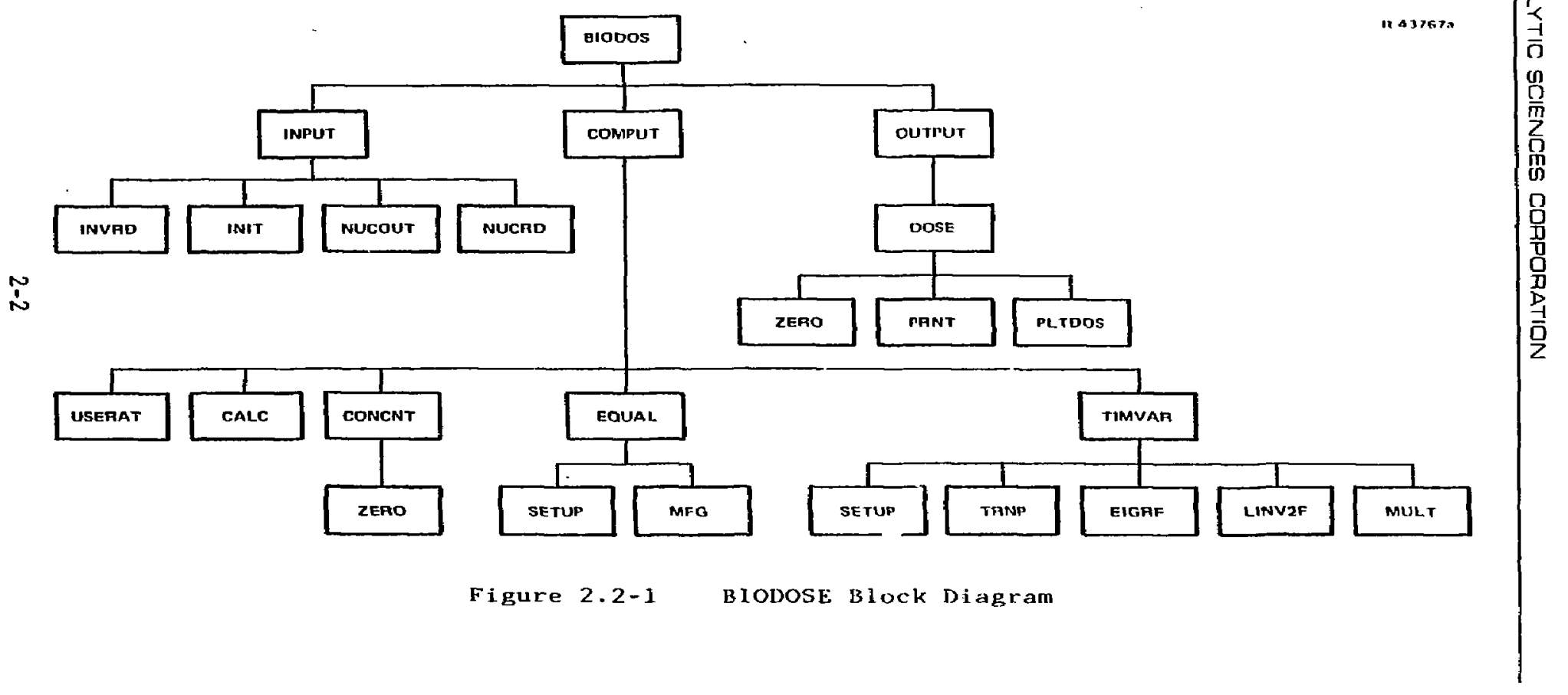




\subsection{SUBROUTINE INPUT - DATA INPUT CONTROLLER}

The soubroutine INPUT controls data input, variable initialization, and echoing of the input data. INPUT uses eight NAMELISTs. The NAMELISTs and their associated defaults are discussed in Section 3.2. Each NAMELIST label corresponds to the labeled common with the same initial letters. Each NAMELIST accepts inputs for variables in the corresponding labeled common. For example, the NAMEIIST SYSLST contains variables that are contained in the labeled common SYSPAR. (See Table 2.3-1.)

TABLE 2.3-1

NAMELIST AND LABELED COMMON BLOCKS

\begin{tabular}{|l|l|l|}
\hline NAMELIST & $\begin{array}{c}\text { LABELLED } \\
\text { COMMON }\end{array}$ & \multicolumn{1}{|c|}{ DESCRIPTION } \\
\hline SYSLST & SYSPAR & Systen control parameters \\
ANLST & ANPAR & Animal product parameters \\
SOILST & SOIPAR & Soil parameters \\
ULST & UPAR & Usage parameters \\
VEGLST & VEGPAR & Vegetable pr duct parameters \\
WLST & WPAR & Water parameters \\
NUCLST & NUCPAR & Nuclide physical parageters \\
INVLST & INUPAR & Nuclide inventory parameters \\
\hline
\end{tabular}

There re two forms on initialization in the program. Default values for all input variables are assigned at run time initialization by the BLOCR DATA subprograms: BLKGEN, BLKLNV, and BLKNIJC. These values can then be overwritten in the NAMELIST input. Dynamic initialization of variables is accomplished in the subroutine INIT, called by INPUT. 
File input is controlled by logical variables in the SYSLST NAMELIST. If INVBIT is set to .TRUE, in the input, the subroutine INVRD is called to read the nuclide inventory file. If NUCBIT is set to.TRUE. the subroutine NUCRD is called to read the nuclide specific parameter file. The files are read before the NAMELISTS are read. Thus, a file may be read, and then its values overwritten by using the appropriate NAMELIST input. INVBIT and NUCBIT are defaulted to .TRUE. .

The input data is echoed, or summarized. The first seven reports are generated by INPUT for every run. They contain the non-nuclide parameters read by the NAMELISTS: SYSLST, ANLST, SOILST, ULST, VEGLST, and WLST. INPUT calls the subroutine NUCOUT to print summaries of the nuclide parameters specified for the current run by the logical array INCLUD.

\subsubsection{Subrout ine INVRD - Nuclide Inventory File Input}

The subroutine INVRD reads the nuclide inventory data from the appropriate file on the logical device specified by the variable IOFILE. First, two parameters are tested against current values as a guard against using the wrong file. Next the inventory sampling times are read. Finally, the inventory values at each time for each nuclide are read. If no files are specified, the default values set in the Block Data BLKINV are used.

\subsubsection{Subroutine INIT - Non-Standard Dose Factor Initialization}

The subroutine INIT initializes variables that depend on inpul data. It transfers the requested number (NTIME) of simulated time points and their associated nuclide inventory values into work arrays. Then variables involving vegetable and water rates are initialized. 
The dose factors (DF50) are modified if both the exposure time (IT1) and the calculation time (IT2) are not 50. The exposure repsonse time is the length of time an individual or population is exposed to nuclide radioactivity; the calculation time is the length of time over which the effects of exposure are calculated.

\subsubsection{Subroutine NUCOUT - Nuclide Data Input Summary}

Subroutine NUCOUT prints input data sumaries of the nuclide parameters requested in the current run by the logical array INCLUD. A nuclide is included in the run if the corresponding flag in the logical array INCLUD is .TRUE.. The default initialization for all elements in the INCLUD array is .TRUE.. For each included nuclide, NUCOUT prints its chemical symbol and inventory sequence number, its fifty year dose factors, various physical and ecological parameters, and a table of inventory parameters.

\subsubsection{Subroutine NUCRD - Nuclide Parameter File Input}

The subroutine NUCRD reads the nuclide specific parameters (DF50, B, FKT, BV, SA, TR, BHL, NCAT, FKS, FKSE, TREAT, and NAME) from the file associated wth logical unit number 10 . If the subroutine NUCRD is not called (when NUCBIT is equal to .FALSE.), the default nuclide parameters in BLKNUC are used. Note that NNUC must equal 36 if the default parameters and inventory are used.

\subsection{SUBROUTINE COMPUT - COMPUTATION CONTROLLER}

The subroutine COMPUT sequences the computation routines. It calls USERAT to calculate usage rates and CALC to calculate potential hazard rates per dose factor. Concentrations in the water system compartments are calculated by one 
of three methods, depending on the value of the system variable ICTYP. If ICTYP is 1 , CONCNT calculates the concentrations by a pre-defined quasi-steady-state solution to the differential equation for concentrations (Eq. $1.2-6$ ). If ICTYP is 2, EQUAL calculates steady-state concentrations by solving the equation $\underline{c}=-A^{-1} q$, where $c$ is the concentration array, $A$ is the transfer matrix, and $g$ is the input array. If ICTYP is 3 , the subroutine TIMVAR is called to calculate the time-varying solution.

\subsubsection{SuDroutine USERAT - Compartment Usage Rate Computation}

The subroutine USERAT calculates usage rates (the matrix U) in each compartment in units per year (e.g., kg/yr, $\ell / \mathrm{yr}, \mathrm{hr} / \mathrm{yr})$. Average individual, maximum individual, or population usage rates are calculated depending on the system variable IDSIG being 1,2 , or 3 , respectively.

\subsubsection{Subroutine CALC - Potential Hazard Rate Computation}

The subroutine CALC computes the potiential hazard rates for each nuclide in each organ from each compartment and category of the pathway excluding the dose factors (DF50). Several general terms are calculated, and the number of water compartments (NWC) in the system are determined. The potential hazard rates per dose factors for each included nuclide are calculated as functions of the usage rates (U). These rates are stored in the BIO arrays in the labeled common BIOPAR. The rate of removal of nuclides is calculated for the individual cases or the population case.

\subsubsection{Subroutine CONCNT - Quasi-Steady-State Computation}

The subroutine CONCNT is one of three alternatives for calculating concentration (in Curies per meter ${ }^{3}$ ) for each 
nuclide in each compartment. CONCNT solves the concentration equations using a pre-defined method (Section 1.2-1). First, constants are initialized, and the concentration matrix (CON) is initialized to zero by a call to ZERO. For each included nuclide, each included compartment and for each time step (loop index J) the concentration is calculated. The system switch TMAX is used to determine the maximum time interval over which water is withdrawn for irrigation.

\subsubsection{Subroutine EQUAL - Steady-State Computation}

The subroutine EQUAL is an alternative method of calculating the nuclide concentrations. It solves the equation $\underline{c}$ $=-A^{-1} \mathrm{q}$ for a steady-state system (Eq. 1,2-16). The arrays are initialized to zero, and the included compartments are determined in the array IC. The routine SETUP is called to compute the transfer rates into and out of each compartment. The inverse of $A$ is calculated by the utility routine MFG. The concentration matrix $\underline{c}$ ( $C O N$ in the program) is $\left(-A^{-1} q\right.$ ), calculated by the utility MULT.

\subsubsection{Subroutine SETUP - Compartment Flow Rates Computation}

The subroutine SETUP calculates the flow rate into and out of each compartment, that is, it sets up the transfer matrix $A$ (FLOWIN in the program). The system variable IC indicates which compartments are included in the current run, and thus controls the dimension of the transfer matrix. For example, if only compartments 1,5 , and 6 are to be included in a simulation, SETUP selects the appropriate $3 \times 3$ transfer matrix $A_{r}$ for each nuclide $r$. 


\subsubsection{Subroutine TIMVAR - Time-Varying Computation}

The subroutine TIMVAR implements the time-varying solution of the compartment model (Section 1.2-1). First, the transfer matrix (FLOWIN) is set by a call to SETUP. Then for each nuclide the time-varying solution is calculated. The appropriate transfer matrix is transposed. The IMSL subroutine ElGRF is called to calculate the eigenvalues (EVALS) and the eigenvectors (EVECS). The inverse of the eigenvectors is calculated. Then for each time, the factors $Q$ (inventory of nuclide in the water system, $Q$ ) and $U$ (fraction of total inventory input to the water system, q) are initialized (see Eq. $1.2-6)$. The results are stored in sequential order in a temporary matrix (TMPCON) and then transferred to the concentrations matrix (CON) via the appropriate subscript transformation corresponding to the original compartment code numbers (Table 1.2-3).

To prevent numerical difficulties, if seven compartments are simulated, TIMVAR should be called twice to solve the compartment concentrations in two stages through the use of the parameter IC $(\ell)$ (see Section 1.2-1). If IC $(\ell)=0$, compartment $\ell$ concentrations are set to zero. If $\operatorname{IC}(\ell)=1$, then compartment $\&$ concentrations are solved on the first pass. If IC $(\ell)=2$, then compartment $\ell$ concentrations are computed on the second pass. Normally for the seven compartment codes listed in Table $1.2-3$, IC should be set equal to $[1,2,2,2,1,1,2]$ for $\ell=1$ to 7 , respectively. In any case, if two passes are used, the first comparment on the first pass should be the river compartment (code 1 ) and on the second pass the estuary compartment (code 2) should be called first by setting $I C(2)=2$. 


\subsubsection{Subroutine EIGRF - Eigenvalues and Eigenvector Computation}

The subroutine EIGRF is a product of International Mathematical and Statistical Libraries, Inc. (IMSL), Houston, Texas. It is available in the IMSL Library 1 (Ref. 6). EIGRF computes eigenvalues and eigenvectors of a real matrix. The eigenvectors are not normalized in this routine.

\subsubsection{Subroutine LINV2E - Matrix Inversion}

The subroutine LINV2F is also from the IMSL Library 1 (Ref. 6). LINV2F inverts a real matrix.

\subsubsection{Subroutine DOSE - Potential Hazards Summation}

The subroutine DOSE calculates the requested aggregations of the final potential hazards and calls PRNT to output the results. Because of the number of nuclides, compartments, and categories, the number of final potential hazards is overwhelming. Thus, these final potential hazards may be sunmed across a dimension, or dimensions for output. The facility is controlled by the system variables suMs.

DOSE first initializes the work array to zero. Then for each included nuclide and each time point, intermediate potential hazards are obtained by multiplying the potential hazard per dose factor by the compartment concentrations (Curies per meter $\left.{ }^{3}\right)$. Then for each organ category, compartment and/or nuclide, the potential hazard is calculated by multiplying the intermediate potential hazard by the dose factor (DF50), and a cunning sum is maintained. The results are printed by the routine PRNT. 


\subsubsection{Subroutine PRNT - Potential Hazards Report Printer}

The subroutine PRNT prints the final potential hazard reports in table format. It utilizes a non-exclusive case structure that prints all the tables satisfying a given criterion on the control variable ICODE. Several arrays are set up with the appropriate characters to provide the titles for the reports.

\subsubsection{Subroutine PLTDOS - Potential hazard Plotter}

The subrourine PLTDOS provides graphic displays of potential hazard as a function of time. PLTDOS utilizes subroutines from the DISSPLA package (Ref. 8). Linkage to the DISSPLA routines must be provided if PLTDOS is to be used. PLTDOS is called if the paraneter PLOT is set to.TRUE.. The three-digit code number which appears on the graph for convenience in identifying some key parameters of the simulation is the following:

$$
100 \div(\text { IOFILE- } 1)+10 \div(\text { ISYSTM- } 1+\text { IDSIG- })+(\text { IPORG- } 1)
$$

The parameter IPORG is an input parameter indicating the organ code number to be plotted and has a default value of 1 (whole body equivalent).

\subsection{UTLLITY SUBROUTINES}

There are four support subroutines in program BIOnOSE that perform general purpose functions. These routines are called from numerous other subprograms and are not described in the previous program description sections. The implementation and usage of each of these routines is straightforward. 
The calling sequence, array and dimensions and purpose of each is summarized below:

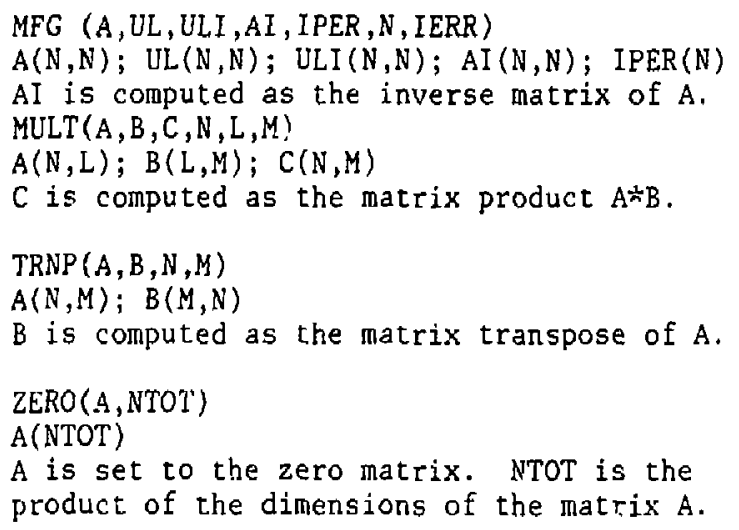

\subsection{BLOCK DATA BLKGEN - GENERAL PARAMETERS INITIALIZATION}

The block data BLKGEN contains the default values for non-nuclide-specific parameters, that is, for those variables in the labeled COMMONS ANPAR, SYSPAR, SOIPAR, UPAR, VEGPAR and WPAR. All variables are initialized (see Tables 3.2-1 through $3.2-8)$.

\subsection{BLOCK DATA BLKINV - NUCLIDE INVENTORY INITIALIZATION}

The block data BLKINV contains the default values for the nuclide inventories, that is, those variables in the labeled common INVPAR. Subscripting in the DATA statements is avoided by array equivalences and FORTRAN-style subscript usage. 
2.8 BLOCK DATA BLKNUC - NUCLIDE PARMAETERS INITIALIZATION

The block data BLKNUC contains the default values for the nuclide physical parameters, that is, the variables in the labeled common NUCPAR. Subscripting in the DATA statement is avoided by array equivalences and FORTRAN-style subscript usage. 
3. PROGRAM USAGE

3.1 INTRODUCTION

The BIODOSE program was designed for the user. Ease of input is achieved through the NAMELIST option with default values assigned for every input variable. Thus the only values required in the input stream are those that differ from the defaults. The inputs are summarized, or echoed, in clear tabular reports.

Since all input variables have default values, the program can be run with null NAMEI.ISTS. The NAMELIST insert sequence for this default run and the output generated are shown in the attachment to this report. The input and output structures are explained in detail in the following sections.

\subsection{PROGRAM INPUTS}

The input strucutre is simple: it consists of 8 NAMELIST input statements. Each NAMELIST refers to a different class of inputs (see Table 2.3-1) and references variables in an associated labeled COMMON. If the default values for a given NAMELIST are satisfactory, then only a null NAMELIST is required in the input. If changes to values are desired, the appropriate value is entered with the associated variable name. This procedure is explained in detail below. A complete list of the NAMLEIST variables and their defaults is given in Tables 3.2-1 through 3.2-8. These inputs are summarized by the INPUT routine. 
TABLE 3.2-1

BIODOSE INPUT DATA SUMMARY, SYSTEM PARAMETERS

(NAMELIST/SYSLST/)

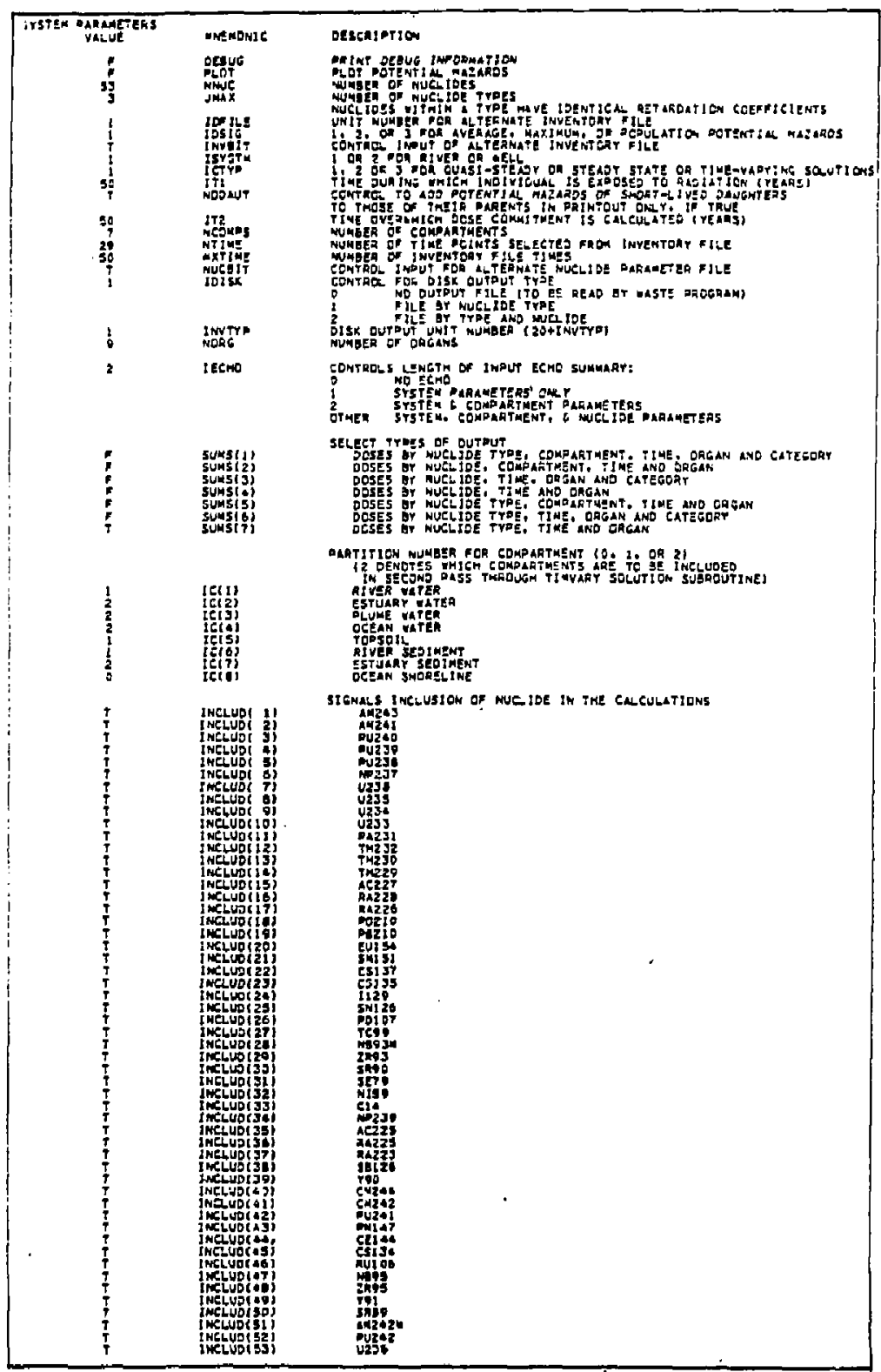


TABLE $3.2-2$

BIODOSE INPUT DATA SUMMARY, ANIMAL PARAMETERS (NAMEIIST/ANLST/)

\begin{tabular}{|c|c|c|}
\hline 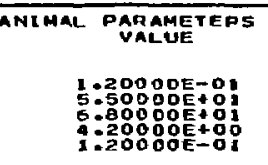 & 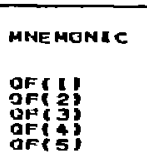 & 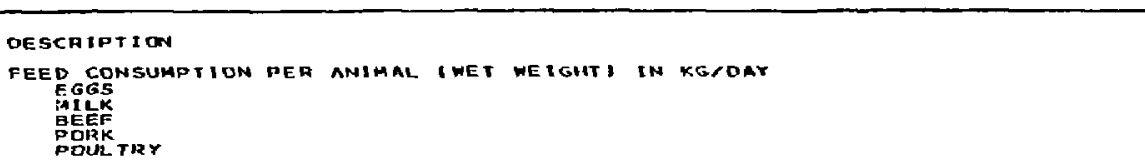 \\
\hline 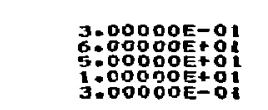 & 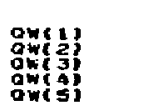 & 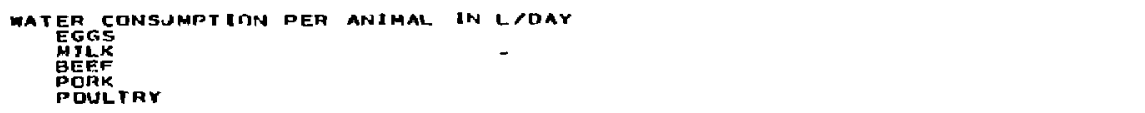 \\
\hline 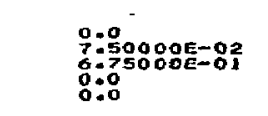 & 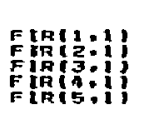 & 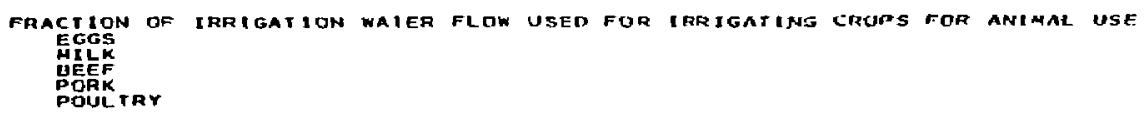 \\
\hline $\begin{array}{l}0.0 \\
0: 50000 E-02 \\
6: 750006-01 \\
0: 0 \\
0.0\end{array}$ & 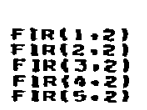 & 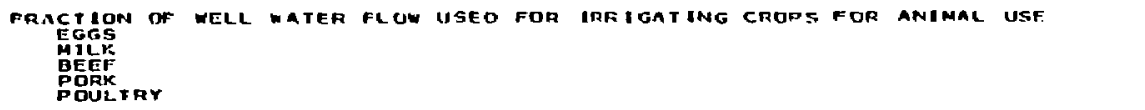 \\
\hline $\begin{array}{l}0: 0 \\
7: 00000-05 \\
5: 50000-04 \\
5: 00 \\
0=0\end{array}$ & 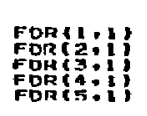 & 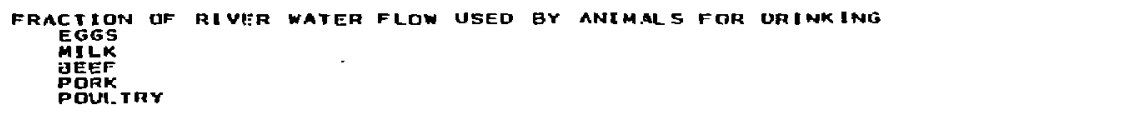 \\
\hline $\begin{array}{l}0: 0 \\
:: 200005=83 \\
:: 20000 \mathrm{E}=02 \\
0: 0\end{array}$ & 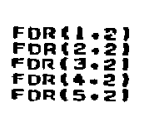 & 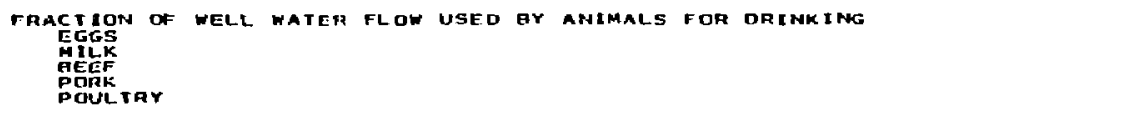 \\
\hline 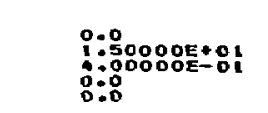 & 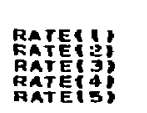 & 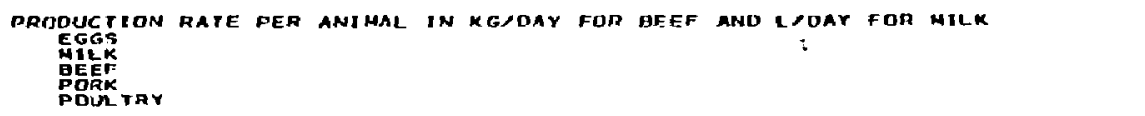 \\
\hline
\end{tabular}



TABLE $3.2-4$

BIODOSE INPUT DATA SUMMARY, USAGE PARAMETER (NAMELIST/ULST)

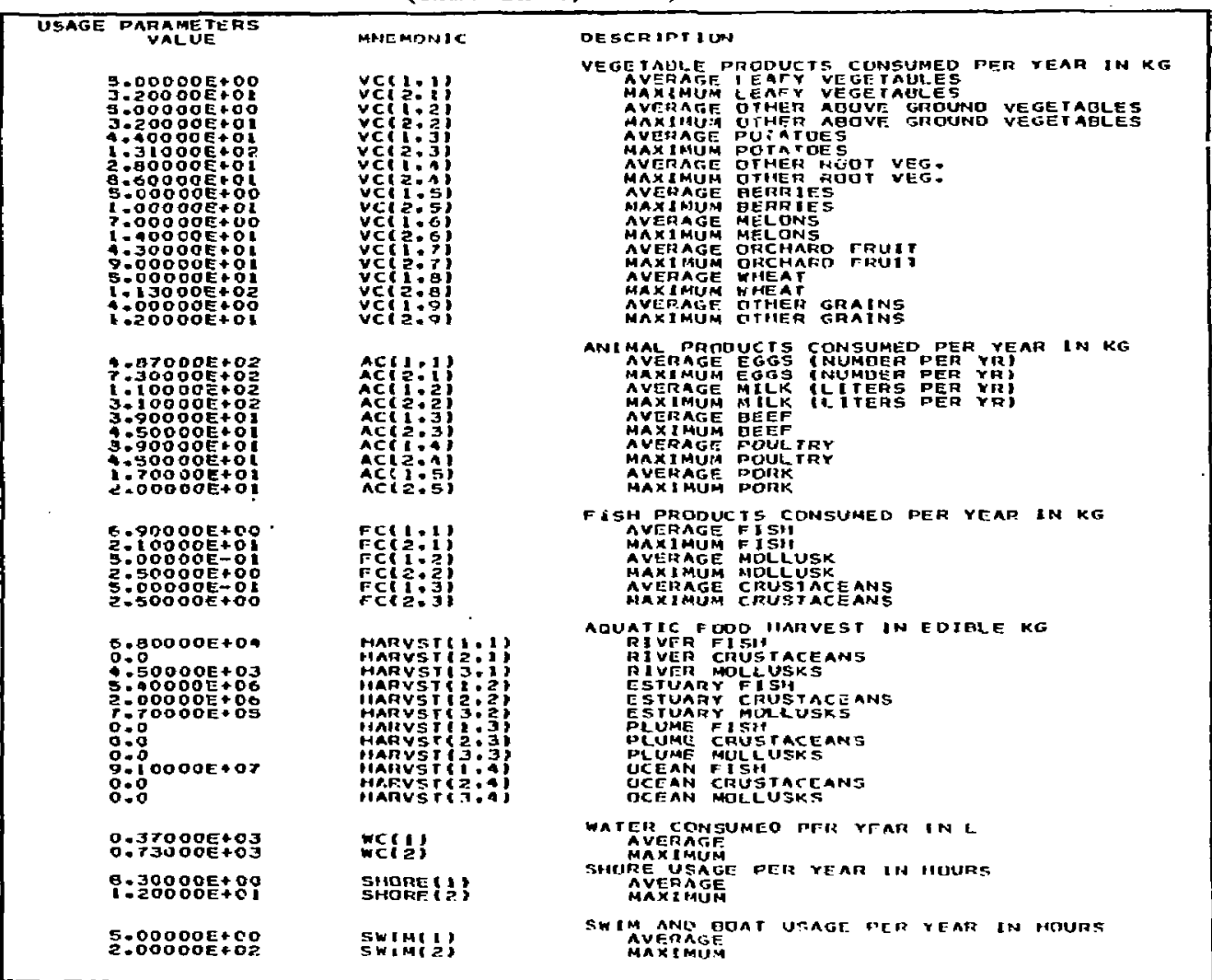


TABLE $3.2 \cdots 4$

BIODOSE INPUT DATA SUMMARY, USAGE PARAMETERS (NAMELIST/ULST) (Continued)

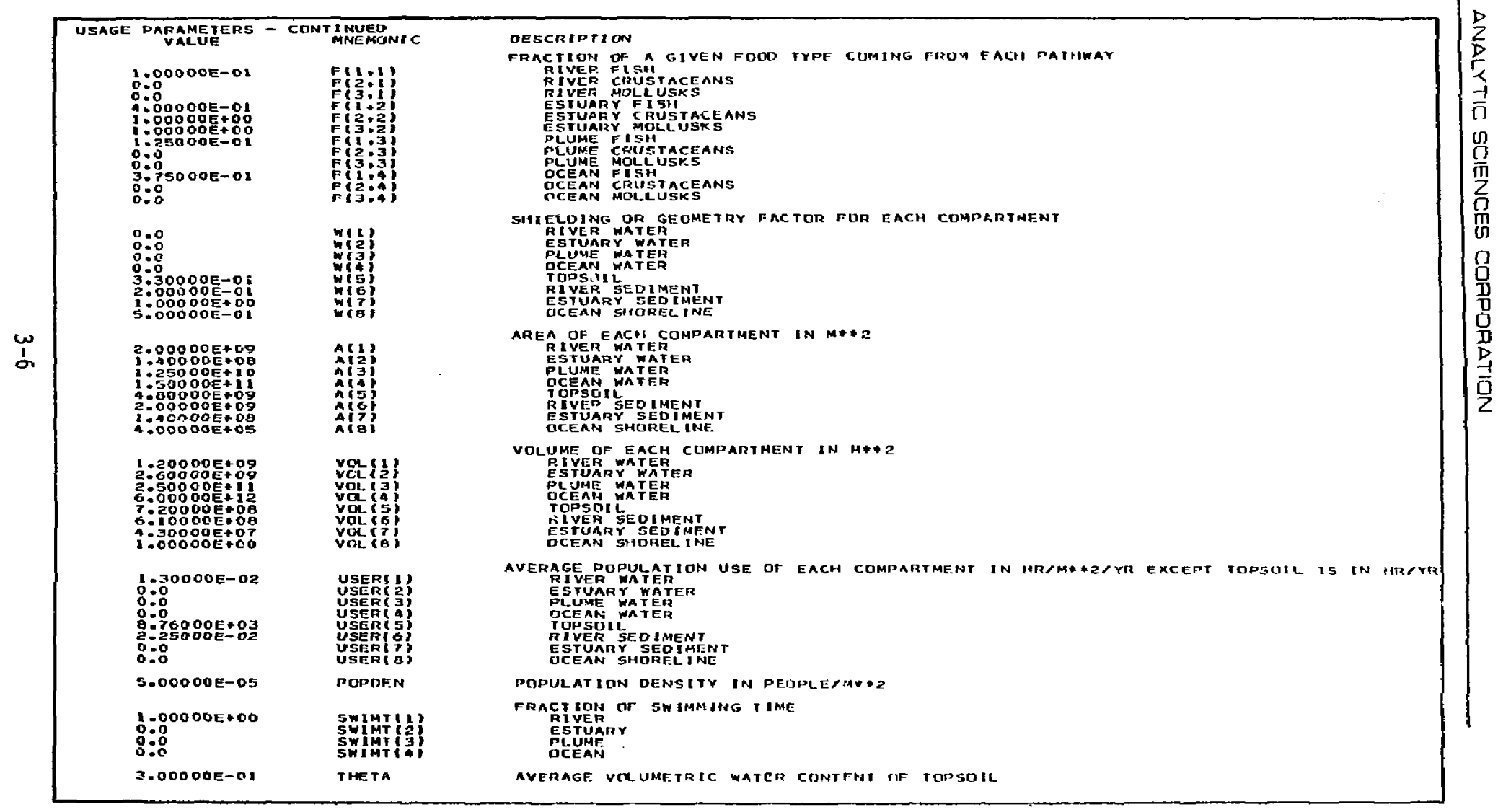




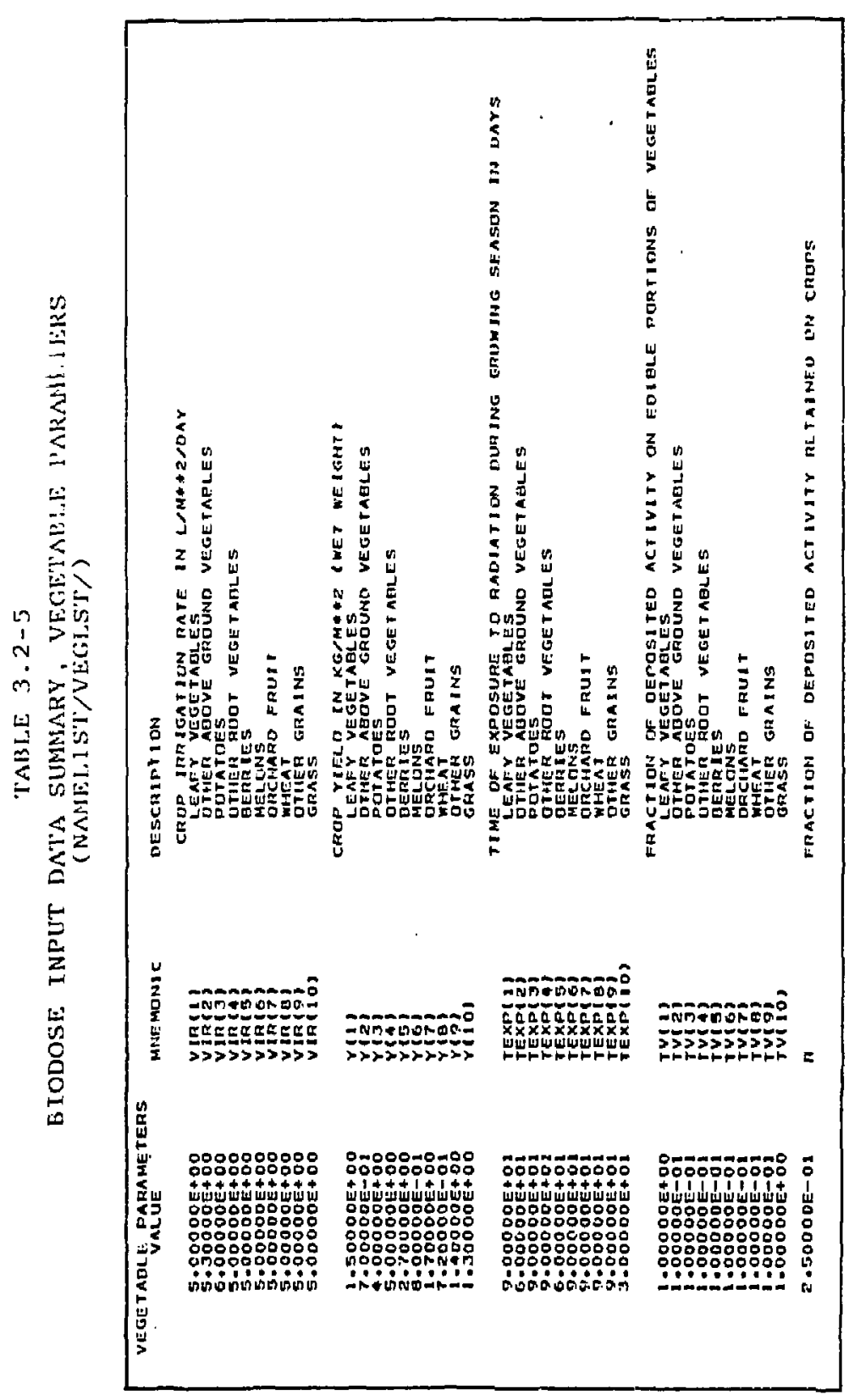



TABLE 3.2-7

NUCLIDE PARAMETERS (NAMELIST/NUCLST/)

\begin{tabular}{|l|l|}
\hline MNEMONIC & \multicolumn{1}{c|}{ DESCRIPTION* } \\
\hline DF50 & $\begin{array}{l}\text { Dose commitment factors for chronic } \\
\text { exposure over 50 years }\end{array}$ \\
B & Water accumulation factors \\
FKT & Soil retention factor \\
BV & Plant concentration factor \\
SA & Transfer coefficients for animal products \\
TR & Atomic half life \\
BHL. & Effective half life in seven organs \\
NCAT & Nuclide category number \\
FKS & River sediment concentration factor \\
FKSE & Estuary sediment concentration factor \\
TREAT & Fraction of nuclide remaining in water \\
& after treatment \\
NAME & Chemical name of nuclide \\
\hline
\end{tabular}

"Default values and units are displayed in output listings (available upon request).

TABLE $3.2-8$

INVENTORY INPUT (NAMELIST/INVLST/)

\begin{tabular}{|c|c|c|}
\hline MNEMONIC & DESCRIPTION & UNITS \\
\hline \hline TIMEIN & Nuclide inventory time & Years \\
VIN & Nuclide inventory value & $\begin{array}{l}\text { Ci/Mwe-yr } \\
\text { per year }\end{array}$ \\
\hline
\end{tabular}

"Default values are displayed in output listings (available upon request). 
There are only a relatively few general rules which govern the specification of values for input parameters through a NAMELIST. Let STATUS represent a general NAMELIST name. Then, the first card in the input deck must contain a blank in the first column, \&STATUS starting in the second column, and a blank in column 9. The specification of individual data items then begins in column 10 of the first data card and continues on succeeding cards if necessary. A data item for an unsubscripted variable is of the form $v=c$ where $v$ is the program mnemonic and $c$ is a constant (e.g., NTRlAL=10 and END=10.0). Data items for subscripted variables are of the form $a=d_{1}, \ldots, d_{j}$ or the form $a(n)=d_{1}, \ldots, d_{m}$ where $a$ is the array name, $n$ is an inceger constant, and the $d_{i}$ are simple constants or repeated constants of the form $k+c$ where $i$ is the repitition factor. With the unsubscripted array name, the total number of constants must equal the number of elements in the array (e.g., $\mathrm{GL}=5.0,5.0,15.0)$. With the subscripted array name, the total number of constants need not equal, but may not exceed, the number of array elements needed to fill the array starting with $\mathrm{a}(\mathrm{n})$ (e.g., $\operatorname{ALAMB}(1)=2.0$ and $\operatorname{PDIAG}(8)=1 . E 7,2.5 E 5)$. All data items must be separated by commas, and any desired number of blanks may be inserted between data items.

The end of a NAMELIST record is indicated by a \&END after the last data item. The \&END may appear directly after the last constant in the data item or may be separated by one or more blanks. For convenience in adding data items to a given NAMELIST, a comma may always be inserted after the last data item and the \&END for the end of the NAMELIST may be placed on the next card.

Three other important points regarding NAMELIST input data should be made. First, there are no restrictions on the order in which the data items are arranged within the list. 
Second, the first colum of every data card, not just the first card, must be left blank; all other 79 columns may be used. Third, the name of every NAMELIST to be read must appear in the input deck, even if no data items are specified for some NAMELIST.

The inventory file, to be read by the subroutine INVRD, should be associated with the value of IOFILE. The variables are listed in the order of the file in Table 3.2-9. The format of the data should be compatible with a FORTRAN unformatted READ statement.

TABLE $3.2-9$

INVENTORY INPUT FILE VARIABLES

\begin{tabular}{|c|}
\hline LNUC $^{*}$ \\
LXTIME $^{*}$ \\
TITLE $(18)^{\dagger}$ \\
TIMEIN (MXTIME) \\
VIN(MXTIME, LNUC)
\end{tabular}

"LNUC is the number of nuclides (must equal NNUC)

LXTIME is the number of time points (must equal MXTIME)

$\dagger$ This title which identifies the inventory type is printed on the second line of every page of output.

The nuclide-specific parameter file to be read by the subroutine NUCRD should be on logical device number 10 . The format should be compatible with FORTRAN unformatted READ statement. The variables are listed in order in Table 3.2-10. 
TABLE $3.2-10$

NUCLIDE-SPECIFIC PARAMETER FILE VARIABLES

DF50(NNUC, 3,9)

$B(N N U C, 2,3)$

FKT (NNUC)

BV (NNUC)

SA (NNUC, 5)

TR (NNUC)

BHL.(NNUC, 7)

NCAT (NNUC)

FKS (NNUC)

FRSE(NNUC)

TREAT (NNUC, 2)

NAME (NNUC, 2)

\subsection{PROGRAM OUTPUTS}

There are two types of printed outputs. The input data summary is described in section 3.2. The final results are printed in a series of tables which show the potential hazards (in rem/MWe or man-rem/MWe-yr for the individual or population, respectively) to each body organ over time. These tables are printed selectively, depending on the value of the control array SUMS. (The array SUMS is described in Table $3.2-1$.

Each report is headed by a title that describes the type of run (average individual, maximum individual, or population) and the category of nuclides in the table. The next 
line contains the inventory title, the third line identifies the path category, and the fourth line identifies the compartment. The potential hazards are printed in a table with the time axis running down the page and the organ running across the page. These are the potential hazards received by the target organ at the time stated. The 'BODY EQUIVALENT' category shows the average, weighted by cancer risks. 
APPENDIX A

SUBPROGRAM CROSS-REFERENCE AND COMMON BLOCK CROSS-REFERENCE

TABLE A-1

SUBPROGRAM CROSS REFERENCES

Calling Subprogram

\begin{tabular}{|c|c|c|c|c|c|c|c|c|}
\hline & $\underset{⿱ 乛}{Z}$ & $\begin{array}{l}\stackrel{H}{S} \\
\stackrel{2}{0} \\
\stackrel{0}{0}\end{array}$ & $\begin{array}{l}\text { H } \\
\text { U } \\
z \\
0 \\
0\end{array}$ & 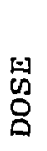 & 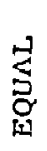 & 苟 & 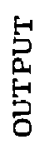 & $\sum_{H}^{\stackrel{n}{S}}$ \\
\hline $\begin{array}{l}\text { CALC } \\
\text { COMPUT } \\
\text { CONCNT } \\
\text { LOSE } \\
\text { EQUAL } \\
\text { EIGRF } \\
\text { INIT } \\
\text { INPUT } \\
\text { INVRD } \\
\text { LINV2F } \\
\text { MFG } \\
\text { MULT } \\
\text { NUCOUNT } \\
\text { NUCRD } \\
\text { OUTPUT } \\
\text { PLTDOS } \\
\text { PRNT } \\
\text { SETUP } \\
\text { TIMVAR } \\
\text { TRNP } \\
\text { USERAT } \\
\text { 2ERO }\end{array}$ & $x$ & $\begin{array}{l}X \\
X \\
X\end{array}$ & $X$ & $\begin{array}{l}X \\
X\end{array}$ & $X$ & $\begin{array}{l}X \\
X\end{array}$ & $X$ & $\begin{array}{l}X \\
X \\
X\end{array}$ \\
\hline
\end{tabular}

"Suhprograms not calling other subprograms are not listed. 
TABLE $A-2$

COMMON BLOCK CROSS REFERENCES

Cormon Block

\begin{tabular}{|c|c|c|c|c|c|c|c|c|c|c|}
\hline & 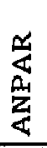 & 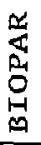 & 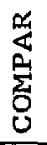 & 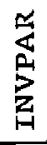 & 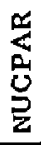 & 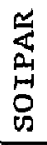 & 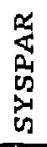 & 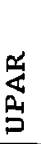 & $\begin{array}{l}\stackrel{a}{4} \\
0 \\
0 \\
0 \\
p\end{array}$ & $\frac{a}{3}$ \\
\hline $\begin{array}{l}\text { BLKGEN } \\
\text { BLKINV } \\
\text { BLKNUC }\end{array}$ & $x$ & & & $X$ & $X$ & $X$ & $X$ & $X$ & $\mathrm{X}$ & $X$ \\
\hline & $X$ & $X$ & & & $\begin{array}{l}X \\
X\end{array}$ & $\mathrm{X}$ & $\begin{array}{l}X \\
X\end{array}$ & $\mathrm{x}$ & $\mathrm{X}$ & $X$ \\
\hline CONCNT & & & & $\mathrm{X}$ & $x$ & $\mathrm{X}$ & $\mathrm{X}$ & $\mathrm{X}$ & & $x$ \\
\hline $\begin{array}{l}\text { DOSE } \\
\text { EQUAL }\end{array}$ & & $X$ & $X$ & $\begin{array}{l}x \\
x\end{array}$ & $\begin{array}{l}X \\
X\end{array}$ & & $\begin{array}{l}X \\
X\end{array}$ & & & \\
\hline INIT & & & & & $X$ & & $X$ & & & \\
\hline INPUT & $\mathrm{X}$ & & & $x$ & $X$ & $\mathrm{X}$ & $X$ & $\mathrm{X}$ & $X$ & $x$ \\
\hline INVRD & & & & $X$ & & & $X$ & & & \\
\hline NUCOUT & & & & $X$ & $X$ & & $X$ & & & \\
\hline NUCRD & & & & & $X$ & & & & & \\
\hline OUTPUT & & & & & & & $X$ & & & \\
\hline PLTDOS & & & & $X$ & & & $X$ & & & \\
\hline PRNT & & & & $X$ & $x$ & & $X$ & & & \\
\hline SETUP & & & $X$ & & $\mathrm{X}$ & $x$ & $\mathrm{X}$ & $X$ & & $\mathrm{X}$ \\
\hline TIMVAR & & & $X$ & $X$ & $X$ & $X$ & $X$ & $\mathrm{X}$ & & $\mathrm{X}$ \\
\hline USERAT & $X$ & & & & & & $X$ & $\mathrm{X}$ & $\mathrm{X}$ & $X$ \\
\hline
\end{tabular}

I

1

1 


\section{REFERENCES}

1. Berman, L.E., et al., "Analysis of Some Nuclear Waste Management Options," The Analytic Sciences Corporation, Report No. TR-1103-1-1, Lawrence Livermore Laboratory Report No. UCRL-13917, October 1978.

2. Strom, P.O., and Watson, E.C., "Calculated Doses from Inhaled Transuranium Radionuclides and Potential Risk Equivalence to Whole-Body Radiation," Transuranium Nuclides in the Environment, IAEA, Vienna, 1976, pp. $603-626$.

3. Burkholder, H.C., et al., "Incentives for Partitioning High-Level Waste," Battelle Pacific Northwest Laboratories, BNWL-1927, November 1975.

4. "Reactor Safety Study: An Assessment of Accident Risk in U.S. Commercial Nuclear Power Plants. Appendix VI. Calculation of Reactor Accident Consequences," U.S. Nuclear Regulatory Commission, WASH-1400, October 1975.

5. "Calculation of Annual Dose to Man from Routine Releases of Reactor Effluents for the Purpose of Evaluating Compliance with 10 CFR Part 50, Appendix I, U.S. Nuclear Regulatory Conmission, Office of Standards Development, Regulatory Guije 1.109, March 1976.

6. "IMSL Library 1 Reference Manual, Volume 1," Edition 6, International Mathematical and Statistical Libraries, Inc., Houston, Texas, IMSL LIBI-0006, July 1977.

7. Ross, B.I., Koplik, C.M., Giuffre, M.S., Hodgin, S.P., and Duffy, J.J., "NUTRAN: A Computer Model of LongTerm Hazards from Waste Repositories," The Analytic Sciences Corporation, Report No. TR-1797-7, December 1979.

8. Integrated Software Systems Corporation, "DISSPLA User's Manual," Version 7.5, December 1978. 